\title{
Posterior parietal cortex and episodic retrieval: Convergent and divergent effects of attention and memory
}

\author{
J. Benjamin Hutchinson, ${ }^{1,3,4}$ Melina R. Uncapher, ${ }^{1,3}$ and Anthony D. Wagner ${ }^{1,2}$ \\ ${ }^{1}$ Department of Psychology, Stanford University, Stanford, California 94305-2130, USA; ${ }^{2}$ Neuroscience Program, Stanford \\ University, Stanford, California 94305-2130, USA
}

\begin{abstract}
Functional neuroimaging studies of humans engaged in retrieval from episodic memory have revealed a surprisingly consistent pattern of retrieval-related activity in lateral posterior parietal cortex (PPC). Given the well-established role of lateral PPC in subserving goal-directed and reflexive attention, it has been hypothesized that PPC activation during retrieval reflects the recruitment of parietal attention mechanisms during remembering. Here, we evaluate this hypothesis by considering the anatomical overlap of retrieval and attention effects in lateral PPC. We begin by briefly reviewing the literature implicating dorsal PPC in goal-directed attention and ventral PPC in reflexive attention. We then discuss the pattern of dorsal and ventral PPC activation during episodic retrieval, and conclude with consideration of the degree of anatomical convergence across the two domains. This assessment revealed that predominantly divergent subregions of lateral PPC are engaged during acts of episodic retrieval and during goal-directed and reflexive attention, suggesting that PPC retrieval effects reflect functionally distinct mechanisms from these forms of attention. Although attention must play a role in aspects of retrieval, the data reviewed here suggest that further investigation into the relationship between processes of attention and memory, as well as alternative accounts of PPC contributions to retrieval, is warranted.
\end{abstract}

Episodic memory-declarative memory for events—has long been known to depend on the medial temporal lobe and, to a lesser extent, the prefrontal cortex (Squire 1992; Shimamura 1995; Wheeler et al. 1995; Gabrieli 1998; Eichenbaum and Cohen 2001; Squire et al. 2004). Recently, an explosion of functional neuroimaging studies has revealed that episodic retrieval is also consistently associated with activity in lateral posterior parietal cortex (PPC), including in the intraparietal sulcus and inferior parietal lobule (Figs. 1, 2; for detailed review, see Wagner et al. 2005; Cabeza 2008; Cabeza et al. 2008; Ciaramelli et al. 2008; Vilberg and Rugg 2008b; Olson and Berryhill 2009). This unexpected finding raises the possibility that parietal mechanisms may be more central to episodic retrieval than previously thought.

At the neuropsychological level, human lesion evidence regarding the necessity of lateral PPC mechanisms for episodic retrieval is limited and mixed (Berryhill et al. 2007; Davidson et al. 2008; Haramati et al. 2008; Simons et al. 2008). By contrast, other neuropsychological data indicate that lateral PPC is unambiguously associated with another cognitive domain-attention (Posner et al. 1984; Mesulam 1999; Parton et al. 2004). This latter lesion literature is further complemented by rich functional neuroimaging evidence implicating dorsal and ventral PPC in goal-directed and reflexive attention, respectively (for review, see Corbetta and Shulman 2002; Corbetta et al. 2008).

Drawing from the rich literature linking attention to lateral PPC, memory researchers have recently proposed that lateral PPC activity during episodic retrieval tasks reflects the engagement of attention mechanisms during remembering (Cabeza 2008; Cabeza et al. 2008; Ciaramelli et al. 2008; Olson and Berryhill 2009).

\footnotetext{
${ }^{3}$ These authors contributed equally to this work.

${ }^{4}$ Corresponding author.

E-mail jbhutchi@stanford.edu; fax (650) 725-5699.

Article is online at http://www.learnmem.org/cgi/doi/10.1101//m.919109.
}

Specifically, it has been hypothesized that: (1) Dorsal PPC activity during retrieval may reflect the recruitment of goal-directed attention in service of performing retrieval tasks and (2) ventral PPC engagement during retrieval may mark the reflexive capture of attention by mnemonic representations. While prior comprehensive reviews of the neuroimaging literature on parietal correlates of episodic retrieval have documented functional dissociations along the dorsal/ventral axis of lateral PPC, which qualitatively parallel those seen in the attention literature, evaluation of the hypothesis that PPC retrieval activity reflects attention mechanisms further requires an assessment of the degree to which attention and retrieval effects co-localize. Here we review lateral PPC correlates of both episodic retrieval and attention, with the goal of directly assessing to the degree of anatomic overlap.

It should be noted from the outset that the aim of the present review is to evaluate the hypothesis that lateral PPC episodic retrieval effects can be explained in terms of goal-directed and reflexive attention mechanisms. As such, we a priori imposed three constraints that served to focus our treatment of these two substantial literatures. First, while both the dual-attention and memory retrieval literatures focus on effects on the lateral parietal surface, retrieval effects are predominantly left lateralized. Thus, we constrained our analysis of attention and retrieval findings to left lateral PPC. ${ }^{5}$ Second, because prior retrieval reviews focused theoretical discussion on dual-attention accounts, here

\footnotetext{
5Use of the term "lateral parietal" or "lateral PPC" in the present review is in keeping with prior publications in the episodic memory literature, and refers to those aspects of the posterior parietal cortex that fall lateral to the mesial aspect of BA 7 (also referred to as "medial PPC," or the precuneus). Lateral parietal cortex therefore comprises both dorsal and ventral regions of PPC, with the dorsal component consisting of the superior parietal lobule (SPL; the lateral extent of BA 7) and the ventral encompassing the inferior parietal lobule (IPL), including the supramarginal gyrus and temporoparietal junction (SMG and TPJ; BA 40), as well as angular gyrus (AnG; BA 39).
} 


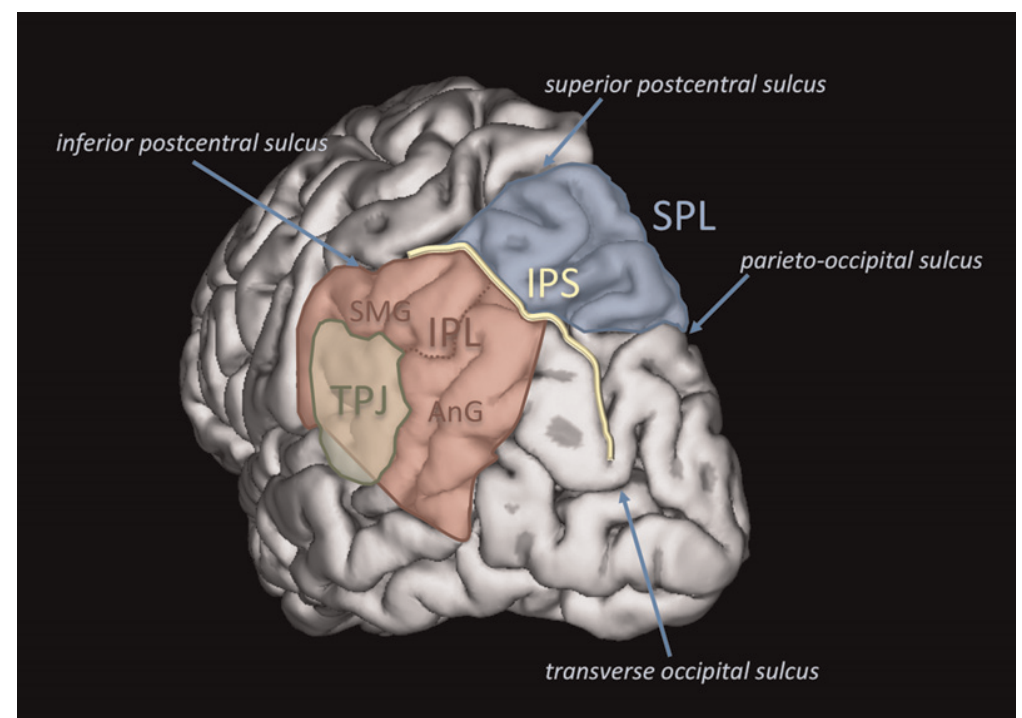

Figure 1. Anatomy of posterior parietal cortex (PPC). A posterior-lateral view of human PPC is depicted, with PPC separated into dorsal and ventral portions by the intraparietal sulcus (IPS). Dorsal PPC includes the superior parietal lobule (SPL) and IPS. Ventral PPC includes inferior parietal lobule (IPL) and its subregions: supramarginal gyrus (SMG), temporoparietal junction (TPJ), and angular gyrus (AnG).

we similarly constrained our treatment of the extensive attention literature to include only those effects relevant to dualattention theory. Finally, because the preponderance of evidence offered in support of dual-attention theory's proposed dorsal attention network derives from studies of visual attention, the present review of the dorsal network is also confined to visual attention. As such, the present review should not be viewed as a comprehensive review of the entire attention literature.

We first survey the functional neuroimaging literature on parietal correlates of goal-directed and reflexive attention, and then discuss how these correlates converge and diverge with the patterns of lateral PPC activity present during episodic retrieval. We conclude by considering theoretical frameworks that focus on the role of attention in episodic retrieval, as well as nonattentionbased accounts of PPC activity during retrieval, and we highlight open questions that await further investigation.

\section{Lateral PPC and attention}

Attention refers to the neurocognitive operations by which an organism is able to selectively process a subset of available information in service of an ongoing task (e.g., James 1890; Cherry 1953; Broadbent 1958; Posner 1980; Treisman and Gelade 1980). It is generally accepted that there are multiple forms and component processes of attention (e.g., Posner and Petersen 1990; Corbetta and Shulman 2002; Husain and Nachev 2007) that emerge from the operations of multiple distributed neural networks (Posner and Driver 1992; Desimone and Duncan 1995; Kastner and Ungerleider 2000; Corbetta and Shulman 2002; Husain and Nachev 2007). Of particular relevance to the present review is the influential body of evidence suggesting that specific fronto-parietal networks mediate fundamental aspects of human attention (for review, see Corbetta and Shulman 2002; Corbetta et al. 2008). Here we focus on the parietal components of these networks, which are held to localize to dorsal and ventral aspects of lateral PPC.

Situated toward the apex of the dorsal visual processing stream, lateral PPC receives input from and provides output to a broad range of cortical areas (e.g., Pandya and Seltzer 1982; Seltzer and Pandya 1986; Wise et al. 1997; Cipolloni and Pandya 1999; Lewis and Van Essen 2003; Rushworth et al. 2006; Schmahmann et al. 2007). Given this high degree of connectivity, it is not surprising that lateral PPC regions have been implicated in a wide variety of functions. Besides attention (e.g., Behrmann et al. 2004), lateral PPC is associated with motor intention (e.g., Andersen and Buneo 2002), decision-making (e.g., Sugrue et al. 2005), mental calculation (e.g., Dehaene et al. 2004; Hubbard et al. 2005), and working memory (e.g., Jonides et al. 1998; Curtis 2006; Raye et al. 2007). Within the domain of attention, converging evidence from neurophysiological, neuropsychological, and neuroimaging studies suggests that lateral PPC supports several interacting attentional processes, including the flexible shifting and allocation of attention in the service of goal-directed selection (Posner and Driver 1992; Goldberg et al. 2002; Pessoa et al. 2003; Behrmann et al. 2004), and reflexive acts, such as reorienting the focus of attention in light of salient or behaviorally relevant information (e.g., Posner et al. 1984; Colby and Goldberg 1999; Corbetta et al. 2008).

An influential development in theorizing about the cognitive neuroscience of attention is Corbetta and Shulman's recent proposal that there are at least two fronto-parietal systems of attention that depend on distinct subregions within lateral PPC (Corbetta and Shulman 2002; Corbetta et al. 2008). Within this dual-attention framework, a "dorsal attention network" - inclusive of bilateral intraparietal sulcus (IPS) and superior parietal lobule (SPL; Fig. 1) - is hypothesized to play a key role in the "top-down" or goal-driven allocation of attention. By contrast, a "ventral attention network"-inclusive of temporal-parietal junction (TPJ), extending into inferior parietal lobule (IPL) - is proposed to support the reflexive reorienting of attention to behaviorally relevant information. We begin by briefly reviewing evidence in support of this distinction between dorsal and ventral PPC attention mechanisms.

\section{Dorsal PPC}

The top-down allocation of attention to goal-relevant information is widely held to arise from a highly interconnected fronto-parietal network that includes dorsal PPC (e.g., Kanwisher and Wojciulik 2000; Corbetta and Shulman 2002; Knudsen 2007). Within dorsal PPC, the IPS and SPL have been consistently associated with the volitional allocation of attention to visual aspects of, and coordinated motor actions to, specific regions in extrapersonal space (e.g., Colby and Goldberg 1999; Culham and Kanwisher 2001; Pessoa et al. 2003; Yantis and Serences 2003). Given that dorsal PPC regions-predominantly left-lateralized IPS—are also associated with successful episodic retrieval, it is critical to understand the manner in which IPS contributes to goal-directed attention, and how these attention mechanisms anatomically converge or diverge with those active during remembering.

The idea that IPS is involved in goal-directed attention is supported by nonhuman primate neurophysiology and human neuroimaging studies requiring covert attention to be directed to specific areas of visual space (for review, see Corbetta and Shulman 2002; Goldberg et al. 2002). For example, robust IPS activity is elicited by external cues directing attention to spatial locations, as well as during tasks requiring sustained spatial attention across 

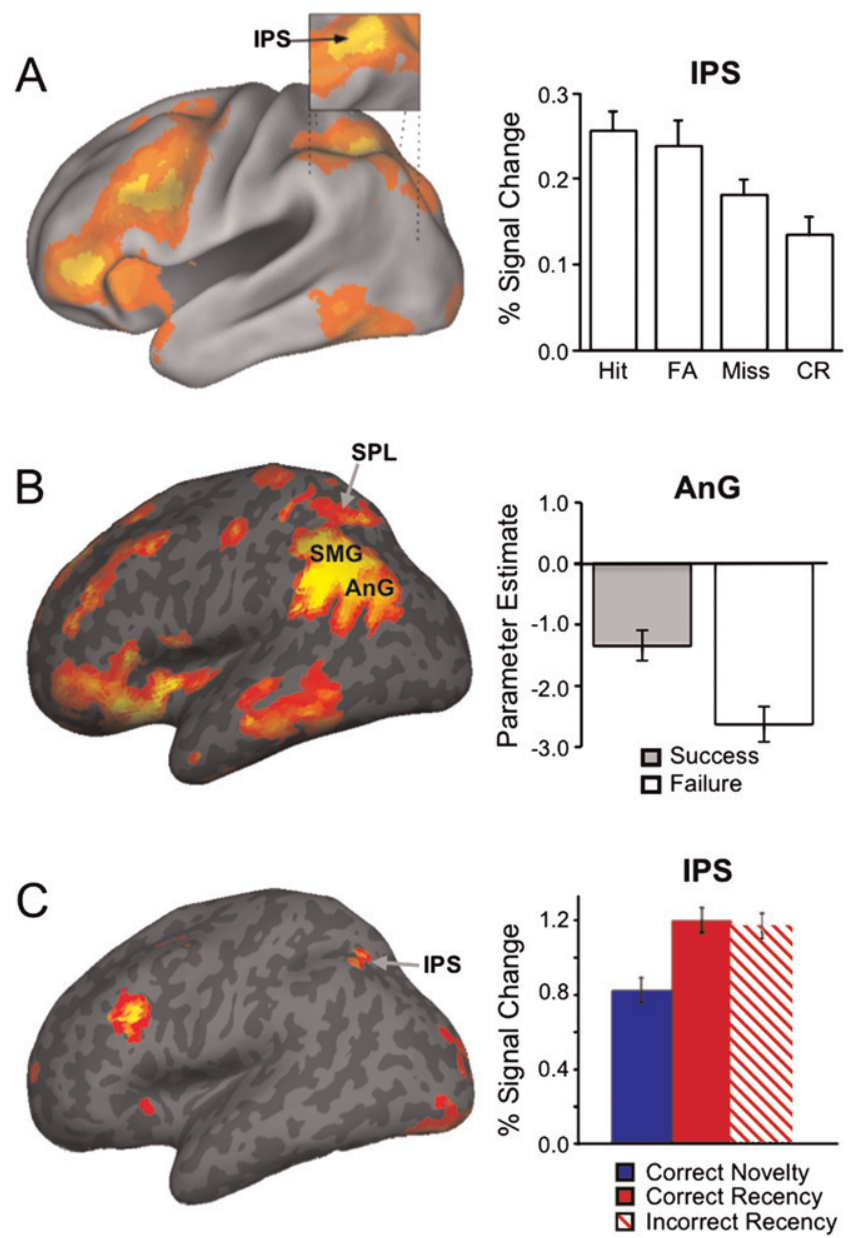

Figure 2. Left lateral PPC activity during episodic retrieval. (A) A comparison of hits relative to correct rejections reported by Kahn et al. (2004) revealed "old/new" effects in dorsal PPC, inclusive of IPS. Average signal change within IPS was greater for items perceived as old (hits and false alarms) vs. those believed to be new (misses and correct rejections). (B) A comparison of successful, relative to unsuccessful, cued recall by Kuhl et al. (2007) revealed greater activity in AnG, compatible with the broader literature on recollection success effects (see Fig. 4). In addition, effects were observed in more anterior aspects of ventral PPC (SMG), as well as in dorsal PPC (principally SPL) (see Discussion). (C) Orienting to memory in attempts to recollect, independent of recollection success, is often associated with activity in dorsal PPC. For example, comparison of temporal recency judgments to novelty-based decisions elicited greater IPS activity (Dudukovic and Wagner 2007).

a delay period (e.g., Corbetta et al. 2000, 2002; Sereno et al. 2001; Curtis et al. 2004; Kincade et al. 2005; Schluppeck et al. 2005; Silver et al. 2005). Extant data further indicate that attentionrelated IPS activity demonstrates a strong spatial specificity, at least in some IPS subregions. In particular, an emerging neuroimaging literature has begun to topographically map the human IPS, identifying visual attention maps along the medial and, to a lesser extent, lateral banks of human IPS, wherein contiguous areas of cortex respond to contiguous areas across overtly and covertly attended retinotopic space. IPS maps have been identified using covert attentional orienting (Silver et al. 2005; Saygin and Sereno 2008), memory-guided saccade (Sereno et al. 2001; Schluppeck et al. 2005, 2006; Hagler et al. 2007; Levy et al. 2007; Konen and Kastner 2008a,b), and passive viewing paradigms (Swisher et al. 2007; cf. Jack et al. 2007). Although across-subject variability is present, extant data currently suggest that there are at least five retinotopically organized attentional maps along human IPS (IPSO-IPS4; Fig. 3). The functional characteristics of these regions have prompted proposals that at least a subset of these attentional maps may be homologous to monkey lateral intraparietal area (LIP) (for discussion, see Sereno et al. 2001; Schluppeck et al. 2005, 2006; Silver et al. 2005; Hagler et al. 2007; Swisher et al. 2007; Konen and Kastner 2008a,b), offering a potentially fruitful anatomic landmark for future exploration of PPC attention mechanisms.

To more fully appreciate the distribution of IPS effects identified in the aforementioned neuroimaging studies of goaldirected visuospatial attention, we plotted on a standardized fiducial brain (Van Essen et al. 2001; Van Essen 2005) the foci from relevant studies cited in reviews by Corbetta and Shulman (Corbetta and Shulman 2002; Corbetta et al. 2008) (see Methods of comparison below for detailed inclusion criteria; Table 1 lists all included foci). Consistent with Corbetta and Shulman's model, Figure 4A (white foci) reveals a fairly consistent pattern of effects, largely localized to the medial wall of the middle and posterior branches of IPS, and extending superiorly into SPL.

In addition to playing a role during tasks of visuospatial attention, dorsal PPC mechanisms have been proposed to generalize beyond the visuospatial domain (e.g., Coull and Frith 1998; Wojciulik and Kanwisher 1999; Marois et al. 2000a; Yantis and Serences 2003; cf. Husain and Nachev 2007). For example, IPS activity has been associated with directing attention to information that is ostensibly nonspatial in nature, such as shifting attention between (or allocating attention selectively to) superimposed objects at fixation (Yantis and Serences 2003; Serences et al. 2004) or between different features of a particular object (e.g., "attend to either the color or shape of a centrally presented item") (Le et al. 1998; also see Wojciulik and Kanwisher 1999; Shulman et al. 2002; Giesbrecht et al. 2003; Liu et al. 2003).
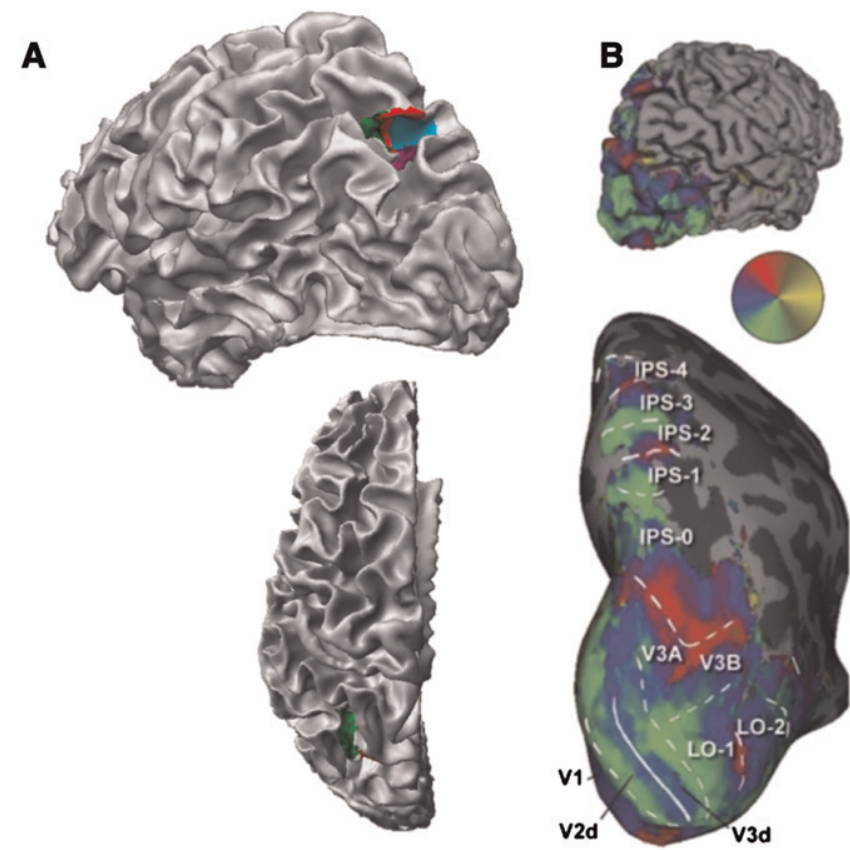

Figure 3. Multiple visuospatial attentional maps are observed along human IPS. (A) Posterior-lateral view (top) and dorsal view (bottom) of left hemisphere surface from a single subject, with delineated maps of IPS 1 (purple), 2 (blue), 3 (red), and 4 (green) (courtesy of Michael Silver). (B) Posterior-lateral view (top) and posterior view (bottom) of right hemisphere surface from a single subject, displaying visual field maps of occipital and dorsal parietal lobes, including IPSO-4, as produced from a rotating wedge stimulus (adapted from Swisher et al. [2007], with permission from The Society for Neuroscience (c)2007). 
Table 1. Published coordinates in left lateral PPC from studies of top-down and reflexive attention, and summary coordinates from prior episodic retrieval meta-analyses (see text for details)

\begin{tabular}{|c|c|c|c|c|c|}
\hline Study & $x$ & $y$ & $z$ & Stimulus domain & Effect of interest \\
\hline \multicolumn{6}{|l|}{ Top-down attention } \\
\hline \multirow[t]{4}{*}{ Astafiev et al. (2003) } & -25 & -63 & 44 & Spatial & Visual orienting (cue activity) \\
\hline & -29 & -61 & 52 & & \\
\hline & -31 & -51 & 46 & & \\
\hline & -17 & -65 & 48 & & \\
\hline Beauchamp et al. (2001) & -26 & -57 & 50 & Spatial & Selective peripheral attention \\
\hline Connolly et al. (2002) & -33 & -45 & 42 & Spatial & Delayed saccade task \\
\hline \multirow[t]{3}{*}{ Corbetta et al. (1998) } & -25 & -55 & 50 & Spatial & Peripheral attention shifting \\
\hline & -19 & -63 & 60 & & \\
\hline & -25 & -75 & 22 & & \\
\hline \multirow[t]{4}{*}{ Corbetta et al. (2000) } & -25 & -67 & 48 & Spatial & Visual orienting (cue activity) \\
\hline & -25 & -57 & 46 & & \\
\hline & -23 & -67 & 32 & & \\
\hline & -27 & -75 & 26 & & \\
\hline \multirow[t]{2}{*}{ Corbetta et al. (2002) } & -27 & -77 & 18 & Spatial & Visual orienting (delay activity) \\
\hline & -25 & -55 & 42 & & \\
\hline \multirow[t]{4}{*}{ Culham et al. (1998) } & -29 & -62 & 51 & Spatial & Selective peripheral attention \\
\hline & -31 & -79 & 22 & & \\
\hline & -18 & -70 & 69 & & \\
\hline & -43 & -39 & 44 & & \\
\hline Hagler and Sereno (2006) & -23 & -79 & 32 & Spatial & Attention mapping \\
\hline \multirow[t]{6}{*}{ Hopfinger et al. (2000) } & -44 & -64 & 32 & Spatial & Visual orienting (cue activity) \\
\hline & -44 & -48 & 36 & & \\
\hline & -16 & -52 & 56 & & \\
\hline & -16 & -56 & 56 & & \\
\hline & -40 & -64 & 28 & & \\
\hline & -40 & -48 & 32 & & \\
\hline Jack et al. (2007) & -30 & -58 & 47 & Spatial & Delayed saccade task \\
\hline \multirow[t]{2}{*}{ Kastner et al. (1999) } & -27 & -78 & 38 & Spatial & $\begin{array}{l}\text { Visual orienting } \\
\text { (expectation activity) }\end{array}$ \\
\hline & -18 & -63 & 54 & & \\
\hline \multirow[t]{6}{*}{ Kincade et al. (2005) } & -38 & -50 & 50 & Spatial & Visual orienting (cue activity) \\
\hline & -23 & -57 & 54 & & \\
\hline & -13 & -59 & 51 & & \\
\hline & -27 & -59 & 34 & & \\
\hline & -38 & -50 & 46 & & \\
\hline & -19 & -60 & 52 & & \\
\hline \multirow[t]{2}{*}{ Pessoa et al. (2002) } & -22 & -61 & 43 & Spatial & Working memory (delay period) \\
\hline & -38 & -43 & 39 & & \\
\hline Rowe et al. (2000) & -22 & -62 & 60 & Spatial & Working memory (delay period) \\
\hline Sapir et al. (2005) & -41 & -56 & 49 & Spatial & $\begin{array}{l}\text { Visual orienting (cue by } \\
\text { performance interaction) }\end{array}$ \\
\hline \multirow[t]{2}{*}{ Schluppeck et al. (2005) } & -21 & -76 & 42 & Spatial & Delayed saccade \\
\hline & -18 & -71 & 52 & & \\
\hline \multirow[t]{13}{*}{ Shulman et al. (1999) } & -25 & -73 & 22 & Spatial & Visual orienting (cue activity) \\
\hline & -29 & -57 & 56 & & \\
\hline & -31 & -53 & 48 & & \\
\hline & -29 & -49 & 40 & & \\
\hline & -13 & -67 & 56 & & \\
\hline & -23 & -71 & 46 & & \\
\hline & -13 & -77 & 46 & & \\
\hline & -29 & -83 & 24 & Spatial & Visual orienting (directionally \\
\hline & -29 & -57 & 56 & & selective cue activity) \\
\hline & -29 & -47 & 40 & & \\
\hline & -25 & -71 & 22 & & \\
\hline & -23 & -69 & 48 & & \\
\hline & -17 & -71 & 38 & & \\
\hline Shulman et al. (2002) & -35 & -55 & 44 & & Visual orienting (cue activity) \\
\hline Silver et al. (2005) & -23 & -76 & 39 & Spatial & Attention mapping \\
\hline & -19 & -75 & 48 & & \\
\hline Swisher et al. (2007) & -23 & -73 & 40 & Spatial & Attention mapping \\
\hline & -21 & -68 & 52 & & \\
\hline & -25 & -61 & 55 & & \\
\hline & -26 & -57 & 54 & & \\
\hline Sylvester et al. (2007) & -33 & -56 & 48 & Spatial & Visual orienting (cue activity) \\
\hline & -20 & -70 & 47 & & \\
\hline Arrington et al. (2000) & -30 & -35 & 41 & Object & Object-based cuing \\
\hline Huettel et al. (2001) & -22 & -72 & 34 & Object & Visual search \\
\hline Shulman et al. (2003) & -19 & -63 & 44 & Mixed & Visual search \\
\hline
\end{tabular}


Table 1. Continued

\begin{tabular}{|c|c|c|c|c|c|}
\hline Study & $x$ & $y$ & $z$ & Stimulus domain & Effect of interest \\
\hline & $\begin{array}{l}-27 \\
-25\end{array}$ & $\begin{array}{l}-55 \\
-73\end{array}$ & $\begin{array}{l}48 \\
26\end{array}$ & & \\
\hline \multirow[t]{4}{*}{ Wojciulik and Kanwisher (1999) } & -29 & -78 & 23 & Mixed & Overlap across \\
\hline & -31 & -52 & 46 & & Visual attention tasks \\
\hline & -15 & -64 & 48 & & \\
\hline & -26 & -63 & 34 & & \\
\hline \multicolumn{6}{|l|}{ Reflexive attention } \\
\hline \multirow[t]{3}{*}{ Indovina and Macaluso (2007) } & -30 & -58 & 44 & Spatial & Invalidly cued target \\
\hline & -32 & -56 & 40 & & \\
\hline & -12 & -64 & 50 & & \\
\hline Kincade et al. (2005) & -57 & -43 & 31 & Spatial & Invalidly cued target \\
\hline Macaluso and Patria (2007) & -30 & -50 & 40 & Spatial & Invalidly cued target \\
\hline \multirow[t]{2}{*}{ Vossel et al. (2006) } & -42 & -54 & 47 & Spatial & Invalidly cued target \\
\hline & -36 & -48 & 48 & & \\
\hline \multirow[t]{2}{*}{ Bledowski et al. (2004) } & -51 & -29 & 35 & Object & Object oddball \\
\hline & -47 & -40 & 46 & & \\
\hline Braver et al. (2001) & -53 & -27 & 24 & Verbal & Letter oddball \\
\hline Clark et al. (2000) & -61 & -45 & 21 & Verbal & Letter oddball \\
\hline Kiehl et al. (2001) & $\begin{array}{l}-38 \\
-56\end{array}$ & $\begin{array}{l}-48 \\
-41\end{array}$ & $\begin{array}{l}60 \\
30\end{array}$ & Auditory & Auditory oddball \\
\hline \multirow[t]{4}{*}{ Linden et al. (1999) } & -55 & -34 & 33 & Auditory & Auditory oddball \\
\hline & -58 & -40 & 27 & 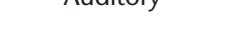 & 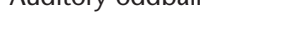 \\
\hline & -55 & -37 & 33 & Object & Visual oddball \\
\hline & -46 & -39 & 46 & & \\
\hline Macaluso et al. (2002) & -58 & -52 & 28 & Spatial/tactile & Invalidly cued target \\
\hline \multirow[t]{2}{*}{ Marois et al. (2000b) } & -21 & -63 & 51 & Object/spatial & Location/identity oddball \\
\hline & -54 & -34 & 23 & & \\
\hline \multirow[t]{2}{*}{ Mayer et al. (2006) ${ }^{a}$} & -42 & -46 & 45 & Auditory & Auditory oddball \\
\hline & -31 & -50 & 37 & & \\
\hline \multirow[t]{2}{*}{ Menon et al. (1997) } & -60 & -32 & 30 & Auditory & Auditory oddball \\
\hline & -56 & -48 & 32 & & \\
\hline \multirow[t]{3}{*}{ Serences et al. (2005) } & -55 & -41 & 17 & Feature & Goal-relevant distraction \\
\hline & -20 & -60 & 41 & & \\
\hline & -26 & -71 & 20 & & \\
\hline Strange and Dolan, $2007^{\mathrm{b}}$ & -48 & -56 & 34 & Verbal & Verbal oddball \\
\hline Study & $x$ & $y$ & $z$ & Memory process & Coordinate type \\
\hline \multicolumn{6}{|l|}{ Episodic retrieval } \\
\hline \multirow[t]{2}{*}{ Ciaramelli et al. (2008) } & -36 & -57 & 42 & "Top-down" & Median coordinate \\
\hline & -50 & -57 & 38 & "Bottom-up" & Median coordinate \\
\hline \multirow[t]{2}{*}{ Vilberg and Rugg (2008b) } & -38 & -62 & 46 & Familiarity & Center of mass \\
\hline & -43 & -66 & 38 & Recollection & Center of mass \\
\hline
\end{tabular}

All coordinates are reported in study-specific space (i.e., Talaraich or MNI).

${ }^{a}$ Coordinates listed for the contrast of interest from this study (validity $\times$ stimulus onset asynchrony interaction) included a location in angular gyrus. However, this data point did not show a simple effect of validity (invalid > valid) and was thus omitted.

${ }^{b}$ Although coordinates listed here were only given for an interaction between a placebo and drug group, the text and figures from this study suggest that an oddball effect was present in the placebo group.

It is worth noting that such paradigms indexing attention to objects do not definitively preclude the deployment of spatial attention, because successful attentional allocation to one of two superimposed items, for example, might require slight shifts of spatial attention to favor the processing of discriminating features occupying distinct locations. Also, although there is evidence that selective feature-level attention might be separable from visuospatial attention (e.g., Serences and Boynton 2007), the current review does not contain studies that unambiguously isolate this feature-level processing.

To determine whether any dissociations are apparent within lateral PPC that might ultimately relate to whether episodic retrieval deploys spatial vs. "nonspatial" goal-directed attention, we returned to the Corbetta and Shulman reviews (Corbetta and Shulman 2002; Corbetta et al. 2008) to plot foci from studies examining goal-directed attention to objects and features of objects (see Methods of comparison section for details). As with spatial effects, visual object/feature effects fall largely within posterior IPS and in SPL (Fig. 4A, gray foci; Table 1). These findings fit with existing theories proposing that a fronto-parietal network, including IPS and SPL, might be involved in attentional control across various types of visual information (e.g., Yantis and Serences 2003). Although it has been proposed that SPL and IPS support distinct attention mechanisms (e.g., SPL is putatively involved in shifts of visuospatial attention, and IPS in the representation of attentional priority maps) (Molenberghs et al. 2007), such distinctions between different aspects of visual attention within dorsal PPC are outside the scope of the current review. In sum, allocating visual attention in a goal-directed manner consistently recruits dorsal PPC mechanisms.

\section{Ventral PPC}

The ventral attention system is held to enable attentional capture by, and reorientation to, salient or behaviorally relevant stimuli. 

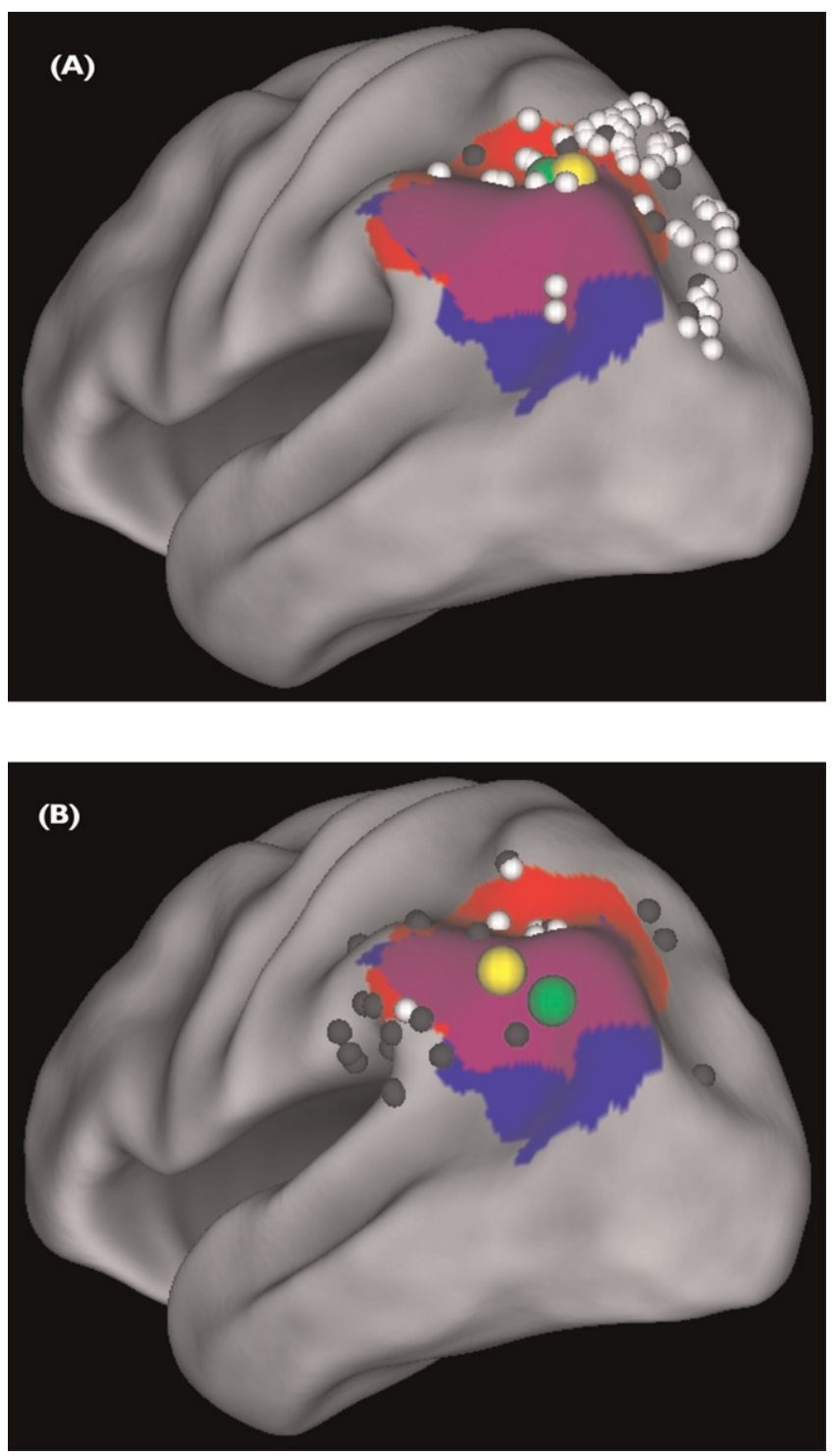

Figure 4. Attention and episodic retrieval fMRI effects in human PPC projected onto a fiducial cortical surface. Representative foci from attention studies are overlaid on retrieval convergence maps of old/new effects (red), recollection effects (blue), and their overlap (purple). (Figure adapted from Wagner et al. [2005] and reprinted with permission from Elsevier @ 2005 .) Colored areas represent regions activated at $P<0.001$ in four or more of the seven contrasts of hits vs. correct rejections (i.e., old/ new effects) and two or more of the four contrasts targeting recollection effects. Attention foci were surface-rendered onto a fiducial brain (PALSB12) using Caret Software (http://www.nitrc.org/projects/caret/) (Van Essen 2005). (A) Foci from studies of top-down visuospatial (white) and visual object/feature (gray) attention are plotted, along with the summary foci from the Vilberg and Rugg (2008b) (green) and Ciaramelli et al. (2008) (yellow) studies of "familiarity-based" retrieval effects. (B) Foci from studies of bottom-up visuospatial (white) and nonvisuospatial attention (gray) are plotted, along with the summary foci from the Vilberg and Rugg (2008b) (green) and Ciaramelli et al. (2008) (yellow) studies of "recollection-based" retrieval effects. See Table 1 for full list of coordinates.

Extant evidence suggests that this second system is mediated in part by ventral PPC mechanisms, with a prevalent right hemispheric lateralization (Corbetta and Shulman 2002; Stevens et al. 2005; Corbetta et al. 2008). In human neuroimaging studies, for example, activity in the supramarginal gyrus (SMG) and TPJ is often sensitive to infrequently occurring (e.g., "oddball") or unanticipated stimuli that attract attention (e.g., McCarthy et al. 1997; Linden et al. 1999; Clark et al. 2000; Marois et al. 2000b; Braver et al. 2001; Kiehl et al. 2001; Stevens et al. 2005).

Within the visuospatial domain, evidence from human lesion and neuroimaging studies suggests that ventral parietal mechanisms facilitate the reorientation of attention. For example, neural insult typically in the vicinity of right TPJ can produce spatial attention impairments, such as unilateral neglect (Mort et al. 2003; Hillis et al. 2005) (it should be noted that damage to left ventral PPC can produce deficits in other domains, such as language [e.g., Dronkers et al. 2004]). It has been suggested that ventral parietal damage impacts reflexive attention processes more so than goal-driven processes (e.g., Corbetta and Shulman 2002), leading to disproportionate difficulties in reorienting to behaviorally relevant stimuli in the contralesional visual field (Posner et al. 1984). However, the dorsal and ventral attention networks are posited to dynamically interact (Corbetta et al. 2008). This is partially evidenced by the consistent observation that lesions to ventral PPC can also impact goal-driven processes, as well as dorsal PPC function (e.g., Mesulam 1999; Corbetta et al. 2005; He et al. 2007). Additionally, numerous neuroimaging studies indicate that parietal mechanisms, located primarily in TPJ and SMG, are engaged when a reflexive reorientation of spatial attention is required, such as when task-relevant visual targets appear in spatially unattended or noncued locations (e.g., Arrington et al. 2000; Corbetta et al. 2000, 2002; Macaluso et al. 2002; Kincade et al. 2005; Serences et al. 2005; Vossel et al. 2006; Indovina and Macaluso 2007).

Complementing the aforementioned neuropsychological and neuroimaging evidence are single-unit studies of nonhuman primates that implicate ventral PPC mechanisms when salient stimuli attract attention. For example, neurons in ventral PPC (area 7a) appear to detect and signal the location of visually salient items (e.g., a red square among an array of green squares) (Constantinidis and Steinmetz 2001, 2005). In contrast to the human data, however, the degree of task relevance does not appear to be a necessary factor for driving the ventral PPC response in macaques. Thus, while some have noted the similarity between macaque area $7 \mathrm{a}$ and the human ventral attention network (Corbetta and Shulman 2002; Corbetta et al. 2008), it remains unclear as to where the homolog of human TPJ might fall in the nonhuman primate.

As with dorsal mechanisms, ventral PPC is implicated in tasks beyond the visuospatial domain. For example, TPJ and SMG are both associated with attentional reorienting across a broad range of modalities, including: (1) oddball paradigms and paradigms where the stimulus is presented in an unexpected location, employing tactile (e.g., Macaluso et al. 2002) or auditory stimuli (e.g., Kiehl et al. 2001; Stevens et al. 2005); (2) centrally presented visual stimuli (e.g., Clark et al. 2000; Marois et al. 2000b; Braver et al. 2001); as well as (3) during task and event boundaries (e.g., Downar et al. 2000; Kurby and Zacks 2008).

As noted above, attentional reorienting effects are predominantly reported in right TPJ/SMG. By contrast, the ventral PPC responses observed in the episodic retrieval literature are primarily left lateralized (see next section). Thus, to enable comparison to the episodic retrieval literature, we plotted foci reported in left PPC in visuospatial (white foci) and nonspatial (gray foci) reflexive orienting paradigms (right PPC foci not depicted; see Methods of comparison section for details). As can be seen in Figure 4B, these foci appear to concentrate in TPJ and SMG, and tend to fall anterior to the angular gyrus (AnG). Two other notable patterns are evident in the figure. First, there exists some co-localization between the foci from visuospatial and nonspatial domains, consistent with the idea that ventral PPC mediates a domaingeneral reorienting of attention (Downar et al. 2000; Macaluso 
et al. 2002; Corbetta et al. 2008). Second, while the ventral foci are predominantly concentrated in TPJ and SMG, many other foci fall in dorsal PPC, along the IPS. The frequent co-occurrence of ventral reorienting effects with dorsal activations has motivated dualattention theorists to propose that while the two networks are functionally distinct (Fox et al. 2006; He et al. 2007), they can operate in concert to carry out various complex tasks (Corbetta et al. 2008). ${ }^{6}$

While the attention functions of dorsal and ventral PPC regions remain a highly active area of investigation, evidence to date appears to point to two dissociable and interacting attention systems. Dorsal parietal mechanisms appear to drive top-down, goal-directed, or endogenous attentional allocation, whereas mechanisms in ventral parietal regions appear to support bottom-up, reflexive, or exogenous attentional reorienting operations that can be informed by the current task goal. We next consider lateral PPC correlates of episodic retrieval.

\section{Lateral PPC and episodic memory retrieval}

Episodic retrieval is a neurocognitive act that depends not only on the MTL, but also on multiple fronto-parietal mechanisms (e.g., Squire 1992; Shimamura 1995; Gabrieli 1998; Wagner 1999; Fletcher and Henson 2001; Dobbins et al. 2002; Ranganath and Knight 2002; Buckner 2003; Bunge et al. 2004; Squire et al. 2004; Woodruff et al. 2005; Kuhl et al. 2008). Episodic retrieval paradigms probe memory for past events, and can include (1) recognition memory judgments about whether an item was previously encountered, which can be based on recollection of the contextual details surrounding the item's past encounter and/or on a contextfree sense of item familiarity (for review, see Yonelinas 2002; Rugg and Yonelinas 2003); (2) cued recall and free recall paradigms that require the recollection of event information that is not present in the retrieval cue; and (3) source memory judgments, which require recollection of the contextual (source) details associated with a previously encountered item (Johnson et al. 1993). Here we selectively review the neuroimaging literature on episodic retrieval, with a focus on the frequently observed activation of dorsal and ventral lateral PPC (Fig. 2).

One of the central lines of evidence implicating PPC in episodic retrieval is the consistent observation that neural activity over or in lateral parietal cortex is enhanced during the recognition of previously encountered items ("hits") relative to the correct rejection of unstudied items ("correct rejections" [CRs])-the socalled "old/new effect." The first reports of parietal old/new effects came from studies using electroencephalography, which revealed event-related potentials (ERPs) that differed in amplitude over (primarily left) lateral parietal scalp sites in response to hits relative to CRs, with an onset of around $400 \mathrm{~ms}$ post-stimulus (for review, see Rugg and Curran 2007). A rich body of evidence suggests that this effect reflects the recollection of contextual details from an episode, rather than simple item familiarity (e.g., Smith 1993; Wilding et al. 1995; Allan et al. 1998; Curran 2000; Curran and Cleary 2003; Woodruff et al. 2006; Vilberg and Rugg 2008a).

Complementing the ERP literature, event-related fMRI studies of episodic retrieval have consistently revealed old/new effects in medial and (usually left) lateral PPC (Fig. 4; for reviews, see also Wagner et al. 2005; Cabeza et al. 2008; Vilberg and Rugg 2008b;

\footnotetext{
${ }^{6}$ Although the number of foci are limited, and thus strong conclusions cannot be drawn at this point, it may be notable that the majority of the dorsal PPC foci elicited under conditions of reflexive orienting fall lateral to the dorsal PPC foci elicited under conditions of goal-directed attentional allocation (Fig. 4). Future within-subject comparison is required to determine whether this possible anatomic divergence is real.
}

Olson and Berryhill 2009). Within lateral PPC, numerous fMRI studies have revealed greater activity in left IPS and IPL for hits vs. CRs (e.g., Henson et al. 1999, 2005; Konishi et al. 2000; Leveroni et al. 2000; McDermott et al. 2000; Donaldson et al. 2001; von Zerssen et al. 2001; Leube et al. 2003; Wheeler and Buckner 2003, 2004; Herron et al. 2004; Kahn et al. 2004; Shannon and Buckner 2004; Weis et al. 2004; Tsukiura et al. 2005; Woodruff et al. 2005; Iidaka et al. 2006), with these old/new effects having been observed using various methods to assess retrieval success (e.g., recognition confidence and source memory paradigms) and different types of stimulus material (e.g., visually presented words and pictures; auditorily presented words; pairs of words and/or objects). Importantly, activity in some lateral PPC subregions appears to track the subjective sense that the item is old (i.e., "perceived familiarity" or "perceived oldness"), as evidenced by greater activity in response to unstudied items misidentified as studied ("false alarms" [FAs]) than for studied items misidentified as unstudied ("misses") (Fig. 2A; Wheeler and Buckner 2003; Kahn et al. 2004). Lateral PPC subregions have also been shown to display a monotonic increase in activity that tracks the subject's confidence that a test probe was studied, regardless of the actual old/new status of the item (Yonelinas et al. 2005). As such, extant fMRI data suggest that lateral parietal old/new effects are distinct from repetition priming (Wagner et al. 2005), in that they track perceived memory status rather than the veridical mnemonic status of an item.

Whereas ERP parietal old/new effects appear to predominantly reflect differences in event recollection, fMRI studies indicate that parietal old/new effects reflect at least two functional mechanisms. In particular, fMRI data indicate that distinct subregions in lateral PPC are modulated by phenomenologically different aspects of memory retrieval, with dorsal PPC activation (principally in IPS) tracking perceived item familiarity and ventral PPC activation (principally in AnG) tracking the recollection of episodic details (Wagner et al. 2005; Vilberg and Rugg 2008b). As we discuss next, this functional distinction within lateral PPC is consistent across laboratories, stimulus sets, and the particulars of the retrieval paradigms (Fig. 4; Wagner et al. 2005; Cabeza et al. 2008; Vilberg and Rugg 2008b).

The functional dissociation between dorsal and ventral PPC regions associated with familiarity and recollection has been observed across numerous types of stimuli and retrieval tasks. One class of retrieval tasks requires volunteers to introspect on and report the basis of their recognition decision. For example, in "remember/know" recognition tasks, volunteers are to give a "remember" response if they recollect any aspect of an item's study episode, and a "know" response if they simply believe they have encountered the item during the study phase, but do not remember any specific details of the study event (Tulving 1985). Although the remember/know paradigm may not cleanly dissociate recollection- from familiarity-based memory decisions (e.g., Donaldson 1996; Dunn 2004, 2008; Wixted 2007; Wais et al. 2008), application of this method has frequently revealed greater activity in or near AnG during remember vs. know responses (e.g., Eldridge et al. 2000; Sharot et al. 2004; Wheeler and Buckner 2004; Woodruff et al. 2005; Montaldi et al. 2006), whereas greater activation is frequently revealed in and around IPS during know responses vs. CRs (e.g., Henson et al. 1999; Sharot et al. 2004; Wheeler and Buckner 2004). Similar dissociable patterns of activity have been reported using tasks that objectively, rather than subjectively, assess memory for event details encountered during an item's study. In one such method, memory is probed for experimentally manipulated study context variables, such as the color, location, or task under which each item was studied (i.e., source memory tasks) (e.g., Cansino et al. 2002; Fan et al. 2003; Lundstrom et al. 2003; Kahn et al. 2004; Kensinger and Schacter 
2006). Correct "source" recognition judgments, which are assumed to reflect recollection, are typically associated with increased activation in or near AnG (e.g., Cansino et al. 2002; Kahn et al. 2004; Kensinger and Schacter 2006), whereas item recognition in the absence of source recollection, which is assumed to reflect familiarity, is typically associated with activation in more dorsal PPC regions (e.g., Kahn et al. 2004; Ragland et al. 2004, 2006).

In addition to PPC modulation according to the memory status of an item (perceived or actual), there is also evidence that the type of mnemonic information that subjects orient toward during retrieval has an influence on lateral PPC activity. For example, several fMRI studies have investigated how neural activation differs when performing forced-choice recognition tasks that require either recollective-based decisions (source memory judgments) or familiarity-based decisions (e.g., novelty detection), using test probes with matched mnemonic histories (e.g., Dobbins et al. 2002, 2003; Dobbins and Wagner 2005). These studies consistently reveal left-lateral PPC activity, including superior IPL and lateral IPS, when comparing retrieval oriented to recollective-based, rather than to familiarity-based information (for review, see Wagner et al. 2005), and this pattern is observed independent of retrieval outcome (i.e., activation was comparable on correct and incorrect recollection-based trials) (Dobbins et al. 2003; see also, Fig. 2C; Dudukovic and Wagner 2007). Such findings highlight the need for interpretive caution, suggesting that parietal effects may not exclusively stem from the (veridical or perceived) mnemonic status of an item, but may also reflect goaldirected mechanisms recruited by the task at hand.

The present study of the functional neuroimaging literature on parietal correlates of episodic retrieval might suggest that lesions of lateral PPC would result in frank episodic memory deficits, yet extant lesion data do not support this prediction. Rather, recent studies of human patients with focal lateral PPC damage have not revealed significant impairments in episodic memory, as measured using yes/no recognition, source recollection, and cued recall (Berryhill et al. 2007; Davidson et al. 2008; Haramati et al. 2008; Simons et al. 2008). Likewise, application of transcranial magnetic stimulation to either left or right IPS during recognition memory decisions has been reported to have no significant impact on performance (Rossi et al. 2006).

The absence of clear mnemonic deficits following parietal lesions should be interpreted with caution, however, because most studies examined the performance of patients with unilateral lesions, and the locus of damage in some of the patients may not have encompassed the lateral PPC regions implicated in functional neuroimaging studies of retrieval (but see Simons et al. 2008). Moreover, while dramatic episodic memory deficits have not been observed, a number of studies have revealed more nuanced deficits in patients with PPC damage. Specifically, emerging data indicate that lateral parietal patients are impaired on some measures of recollection, such as demonstrating a diminished subjective sense of remembering and a decline in the level of details freely recalled from autobiographical memory (Berryhill et al. 2007; Davidson et al. 2008; but also see Simons et al. 2008). Although suggestive, further research is clearly needed, including studies with large sample sizes that afford increased anatomical precision and stronger tests of structure-deficit associations (Bates et al. 2003).

\section{Relating lateral PPC attention and memory effects}

Mounting evidence implicating a role for lateral PPC in episodic retrieval has prompted proposal of at least three possible functional interpretations-the mnemonic accumulator hypothesis, output buffer hypothesis, and attention to internal representa- tions hypothesis (Wagner et al. 2005). The mnemonic accumulator hypothesis parallels accumulator accounts of parietal activation during perceptual decision-making (e.g., Shadlen and Newsome 2001; Ploran et al. 2007; see also Heekeren et al. 2004), in positing that lateral PPC mechanisms might track the accumulation of evidence in service of making a mnemonic decision. The output buffer hypothesis states that lateral PPC serves as a temporary mnemonic store, representing retrieved information from declarative memory, perhaps analogous to the proposed "episodic buffer" (Baddeley 2000; Vilberg and Rugg 2008b). Finally, the attention to internal representations hypothesis postulates that, similar to its role in tasks of selective attention, lateral PPC mechanisms might mediate the shifting and allocation of attention to internal representations. Here we evaluate this third account by considering the relation between dual-attention and episodic retrieval effects in lateral PPC.

Several groups have recently noted that human lateral PPC appears to be functionally dissociated along the dorsal/ventral axis in both the attention and episodic retrieval literatures (Cabeza 2008; Cabeza et al. 2008; Ciaramelli et al. 2008; Olson and Berryhill 2009). Accordingly, two highly related proposals have been advanced: the "dual attentional processes" (DAP) hypothesis (Cabeza 2008) and the "attention to memory" (AtoM) account (Cabeza et al. 2008; Ciaramelli et al. 2008; Olson and Berryhill 2009). According to the DAP hypothesis, dorsal parietal areas involved in the top-down allocation of attention are engaged to accomplish retrieval goals, whereas ventral parietal areas involved in the capture and reorienting of attention are recruited to respond reflexively to recollected event details. As such, this interpretation extends the role of the ventral parietal attention network from that of handling behaviorally relevant external events to additionally dealing with internally generated information, specifically of the kind produced by successful episodic recollection. The AtoM account is largely similar to DAP, but additionally considers the roles of dorsal and ventral PPC mechanisms in various stages of memory retrieval. Specifically, ventral parietal mechanisms are held to act around the time information is successfully retrieved from memory, marking the automatic capture of attention by retrieved memory representations. By contrast, dorsal parietal mechanisms are proposed to operate (1) before the retrieval stage itself, perhaps setting the stage for retrieval by allocating top-down attention toward the maintenance of goal states and cues relevant to retrieval, as well as (2) after retrieval, perhaps to facilitate processes such as monitoring and evaluating the products of retrieval en route to a decision about the mnemonic status of the test item.

The central argument advanced by the DAP/AtoM hypotheses-that dorsal and ventral attention mechanisms are component processes engaged during episodic retrieval—garners support from several lines of evidence. First, although only one fMRI study (to our knowledge) has assessed, within-subjects, whether episodic retrieval and attention-related activity converges, the study did reveal activity in dorsal PPC (in anterior, medial IPS/SPL) during both a cued attention task, as well as during an episodic retrieval task (Cabeza et al. 2003). ${ }^{7}$ Second, Ciaramelli et al. (2008) observed that a dorsal PPC focus implicated in top-down attention and

\footnotetext{
${ }^{7}$ Interestingly, in this same study, there also was a left IPL focus that was more responsive during the episodic retrieval than during the cued attention paradigm, and bilateral TPJ/SMG foci were observed to be more responsive to the cued attention than the episodic retrieval paradigm. Interpretation of these data, as well as the IPS/SPL response that was common to the attention and retrieval paradigms, is complicated, however, because the retrieval activations consisted of a comparison to a low-level baseline, rather than a comparison between retrieval conditions. Thus, it is unclear in this study whether these IPL, TPJ/SMG, and IPS/SPL regions demonstrated an old/new or recollection effect.
} 
a ventral PPC focus implicated in reflexive attention (from Corbetta et al. 2000) fell near the median locations of dorsal and ventral PPC foci observed across episodic retrieval studies.

While DAP/AtoM may provide a coherent account with which to consider the component contributions of dorsal and ventral PPC to episodic memory, the specificity of the anatomical-and thus functional-convergence between the episodic retrieval and attention literatures is still in its preliminary stages. Specifically, because prior reviews of the retrieval literature (Wagner et al. 2005; Cabeza 2008; Cabeza et al. 2008; Ciaramelli et al. 2008; Vilberg and Rugg 2008b; Olson and Berryhill 2009) did not include analogous reviews of the dual-attention literature, the degree to which retrieval and attention effects co-localize in PPC remains unknown. Accordingly, the present study provides an initial evaluation of the dual-attention hypothesis of PPC retrieval effects by assessing the degree of anatomical co-localization between foci from the two literatures.

\section{Methods of comparison}

The aim of the present study is to examine the relationship between the anatomical substrates of top-down and reflexive attention and of episodic retrieval in left lateral PPC. To accomplish this, we first surveyed the corpus of the $\sim 300$ studies cited by Corbetta and Shulman in their reviews of the attention literature (Corbetta and Shulman 2002; Corbetta et al. 2008), in order to identify effects associated with top-down and reflexive attention.

We operationalized "top-down attention" effects as those identified in tasks that Corbetta and Shulman cite as core evidence for their dorsal attention network. Specifically, we included effects from analyses targeting the shifting and/or selective allocation of endogenous visual attention: cue/anticipatory period activity from spatial cuing tasks (e.g., Posner cuing task), delay period activity for spatial cuing or visuospatial working memory tasks, contrasts capturing the shift of selective attention to peripheral stimuli, retinotopic attention mapping paradigms (including delayed-saccade paradigms), object-based cuing tasks, and search period activity from visual search paradigms. To increase the representation of data from IPS regions showing retinotopically organized attentional maps, foci from two additional studies were included (Silver et al. 2005; Swisher et al. 2007). Similarly, we operationalized "reflexive attention" effects as those identified in tasks that Corbetta and Shulman cite as support for their ventral attention network. These effects derive from analyses targeting the reorienting of attention upon encountering unexpected, goalrelevant stimuli: visual reorienting and oddball paradigms (and goal-relevant, infrequent distractor activity in the case of Serences et al. [2005]).

Because the Corbetta and Shulman reviews extend the dualattention account to a broad class of parietal phenomena, we excluded studies indexing these possible extensions (e.g., theory of mind, reorienting between internal and environmental processing, maintenance of task sets, signals for task sets/task switching, attention to or implementation of effectors, transition period or event boundary activity, and effects that are sensitive to purely perceptual salience). Furthermore, we excluded effects that could be construed as indexing multiple operations: Posner-cuing paradigms that collapsed across invalid and valid trials, tasks that were unable to separate cue- and target-period activities, and visual search tasks that did not independently estimate search and detection effects. We further excluded studies that did not use healthy adults or did not publish stereotaxic coordinates. Finally, we restricted the plotted foci to those falling at or lateral to $x=-10$ in Talairach space and posterior to the post-central gyrus of the fiducial brain. Foci were included if they fell within left lateral PPC, defined broadly (posterior, lateral, superior, or inferior parietal cortex), regionally (supramarginal gyrus, SMG; angular gyrus, AnG; intraparietal sulcus, IPS; superior parietal lobule, SPL; inferior parietal lobule, IPL; temporoparietal junction, TPJ), or according to reported approximate Brodmann's area ( $\sim$ BA 7,40 , 39 , or the superior aspect of 19). Foci that met these inclusion criteria are listed in Table 1 and plotted in Figure 4.

Foci from included studies were projected onto a fiducial cortical surface (Van Essen et al. 2001; Van Essen 2005), upon which was overlaid previously reported convergence maps of leftlateral PPC activity during episodic retrieval (Wagner et al. 2005), as well as summary foci from two recent episodic retrieval metaanalyses (Ciaramelli et al. 2008; Vilberg and Rugg 2008b). To the extent that putative top-down attention mechanisms are recruited during episodic retrieval, a large degree of overlap would be expected in dorsal PPC between the loci of old/new effects and those implicated in top-down attention (Fig. 4A). Similarly, to the extent that putative reflexive attentional orienting mechanisms are triggered by recollected event details, a large degree of overlap would be expected in ventral PPC between the loci associated with recollection and those implicated in reflexive attentional reorienting (Fig. 4B).

To enable a statistical comparison between the two literatures, we identified all retrieval foci from the Ciaramelli et al. (2008) and Vilberg and Rugg (2008b) studies that were used to create the summary foci of retrieval effects (Fig. 4, yellow and green foci), and compared them to the attention foci plotted in Figure 4. Analyses were accomplished by first converting the left PPC coordinates reported in each episodic retrieval review into a common coordinate space (Talaraich); foci with $x$ coordinates medial to -10 were omitted. Planned comparisons (Mann-Whitney $U$ ) were then performed as follows: Coordinates $(x, y, z)$ from top-down attention foci were tested against those from relevant retrieval effects in each retrieval review ("familiarity" effects in Vilberg and Rugg [2008b], and "top-down attention to memory" effects in Ciaramelli et al. [2008]). Similarly, coordinates from reflexive attention foci were compared to those of "recollection" (Vilberg and Rugg 2008b) and "bottom-up attention to memory" (Ciaramelli et al. 2008).

\section{Results of comparison}

Initial qualitative comparisons of the overlap between the attention and retrieval effects suggest more divergence than convergence, with this divergence being particularly apparent in ventral PPC. Specifically, as is evident in Figure 4A, top-down attention foci fall largely in the medial bank and posterior portion of IPS, as well as in SPL, whereas the old/new convergence map falls lateral to the majority of the attention foci ( 26 out of the 72 top-down attention foci, or $36.1 \%$, fall within the boundaries of the old/new retrieval map). In ventral PPC, while the majority of reflexive attention foci fall in the right TPJ/SMG (not depicted in Fig. 4B), the reflexive attention foci that fall in the left hemisphere do not appear to overlap with the recollection convergence map (only 4 out of 28 reflexive attention foci, or $14.3 \%$, fall within the boundaries of the recollection map). Rather, the majority of the ventral PPC reflexive attention foci appear situated more anteriorly in left TPJ/SMG, whereas the recollection map predominantly encompasses AnG. As described next, this apparent divergence in dorsal and ventral regions was supported by statistical comparisons.

Turning first to the dorsal effects, the mean ( \pm SD) $x, y, z$ coordinates for top-down attention foci reviewed here are: -26.1 (7.4), -61.5 (10.6), and 43.1 (10.6), whereas the mean ( \pm SD) of the retrieval foci reported in Vilberg and Rugg (2008b) are: -33.0 (9.5), -58.7 (8.0), and 42.3 (8.7); and those reported in Ciaramelli et al. (2008) are: -33.9 (13.4), -58.4 (11.4), and 40.7 (9.1). Statistical comparison revealed a significant difference in the $x$ 
coordinates between top-down attention and retrieval foci from both sets of retrieval data $(P<0.01)$. Thus, the apparent medial/ lateral divergence in dorsal PPC between top-down attention and retrieval effects evident in Figure 4A is supported by a significant difference between the $x$ coordinates of the attention and memory foci.

Turning to the ventral effects, the mean $( \pm S D)$ reflexive attention coordinates are: -43.7 (13.9), -44.8 (10.4), and 36.1 (10.7), whereas the mean recollection coordinates reported in Vilberg and Rugg (2008b) are: -42.3 (8.9), -61.2 (11.2), and 36.7 (9.8), and the mean bottom-up attention to memory coordinates reported in Ciaramelli et al. (2008) are: -42.2 (11.4), -56.4 (10.5), and 35.7 (13.8). Statistical comparison revealed a significant difference between attention and retrieval effects in ventral PPC, as the $y$ coordinates of the reflexive attention foci fall anterior to those of the retrieval foci $(P<0.0001)$. Thus, in addition to the fact that the majority of reflexive attention foci fall contralateral to the majority of recollection effects, it is also the case that reflexive attention foci fall unambiguously anterior to retrieval effects in left ventral PPC.

\section{Discussion and open questions}

The differences reported here between the anatomical localization of attention and episodic retrieval effects within lateral parietal cortex offer initial evidence that parietal retrieval effects might not exclusively draw on the same goal-directed and reflexive attention processes that are at the center of Corbetta and Shulman's dualattention hypothesis. Rather, medial and lateral regions of dorsal PPC might support partially distinct functions in episodic retrieval and tasks of attention, and anterior (TPJ/SMG) and posterior (AnG) regions of ventral PPC appear to cleanly dissociate across tasks of retrieval and attention. Each of these findings will be discussed in turn.

Within dorsal PPC, to the extent that there is lateral/medial dissociation between the neural correlates of episodic retrieval and of goal-directed attention, the question arises as to how to interpret the functional significance of dorsal PPC activation during retrieval. One possibility is that more lateral regions of dorsal PPC mediate attention-based operations over a class of information that is central to episodic retrieval tasks, but not to many of the goal-directed attention tasks reviewed here. For example, it is possible that the inclusion criteria in the present review-which were guided by Corbetta and Shulman's approach (Corbetta and Shulman 2002; Corbetta et al. 2008)—were too restrictive in limiting attentional effects to findings within the visual domain. From this perspective, the more medial regions showing attention effects here might be involved primarily in selective attention to spatial and/or visual object sensory input, whereas more lateral regions (predominantly showing retrieval effects) might act upon different dimensions or types of content that are common to episodic retrieval. This possibility aligns with findings from studies investigating aspects of attention beyond the scope of the present review (e.g., motor selection, maintenance of vigilance, and correlates of the attentional blink), which have revealed effects in lateral IPS and IPL (see Rushworth et al. 2003 and Husain and Nachev 2007 for reviews). Alternatively, Vilberg and Rugg (2008b) have proposed that activity in dorsal PPC during recognition memory tasks may signal the degree of stimulus salience, rather than endogenous selective visual attention per se. To the extent that such alternatives are correct, then the attention and retrieval tasks investigated here may recruit only partially overlapping substrates within a larger, more heterogeneous attention network.

Within ventral PPC, what might account for the divergence between the memory effects found in left-lateralized AnG, and the reflexive attention effects found in right-lateralized and, to a lesser extent, left TPJ/SMG? In terms of the laterality difference in ventral PPC, it has been proposed that left PPC processes may differentially operate on verbal and/or meaningful information, whereas right PPC may operate on sensory and/or meaningless information (Cabeza 2008; Vilberg and Rugg 2008b). Alternatively, others have proposed that the lateralization stems from the processing of internally cued vs. externally cued information, respectively (Ciaramelli et al. 2008). In terms of the observed anterior/posterior dissociation, such a finding mirrors existing evidence for at least two distinct networks within ventral PPC: (1) the ventral-attention reorienting network that includes TPJ and SMG and (2) the so-called "default network" that encompasses more posterior regions including AnG, which has been implicated in internally focused tasks such as episodic retrieval (Corbetta et al. 2008) (also see Buckner et al. [2008] for a recent review of the default network literature). Future research should aim to test accounts of diverging lateralization within ventral PPC, as well as further articulate the functional relationship between anterior and posterior areas in ventral PPC during episodic retrieval.

It is important to stress that while the present review suggests a greater divergence than convergence between the attention and episodic retrieval fMRI literatures in lateral parietal cortex, it may indeed be the case that, under some circumstances, PPC regions implicated in the attention literature are engaged during episodic retrieval. For example, eye movements have been observed to occur during memory search and possibly facilitate episodic retrieval (e.g., Christman et al. 2003; Ehrlichman et al. 2007), which may directly or indirectly relate to why conditions thought to require an effortful search of memory, such as contrasts of lower vs. higher recognition memory confidence judgments, have been observed to recruit SPL (see Cabeza et al. 2008). Although speculative at present, it remains important to appreciate that episodic retrieval may elicit dorsal attention mechanisms under some conditions.

Similarly, although the divergence between the attention and retrieval literatures is even more striking in ventral PPC, it should be emphasized that there also appear to be restricted circumstances, wherein the ventral PPC regions implicated in reflexive attention are engaged during episodic retrieval. For example, Kuhl et al. (2007) examined neural mechanisms supporting episodic cued recall under a condition where there were multiple associates for each cue, and thus competition between mnemonic representations was high. During successful vs. unsuccessful recall, greater activation was observed not only in AnG, but also in more anterior PPC structures, including SMG/TPJ (Fig. 2B). Consistent with the AtoM account of ventral PPC activation during retrieval, one possibility is that this activation of SMG/TPJ marks the recruitment of reflexive attention mechanisms when distracting (i.e., competing) memories are recovered during target memory retrieval (Levy and Anderson 2009). To the extent that this account is correct, then one would predict that there should be a relationship between SMG/TPJ activation and the degree of competition induced by distracting memories, a finding that also was observed in the Kuhl et al. (2007) study.

Because the current review surveyed a range of findings from two literatures, the resulting comparisons unavoidably retain the diminished anatomical precision inherent in group-normalized data, compiled from multiple studies. Such an approach might result in a modest level of spurious co-localization when a more nuanced relationship is actually present. For example, the low spatial precision of this approach may account for the partial overlap of effects in dorsal PPC. As there exists evidence that the functional properties of dorsal PPC can be parcellated at a microanatomical scale (Scheperjans et al. 2008), the degree of true overlap between the mechanisms engaged during attention 
and episodic retrieval may be best assessed by other means. In particular, we believe further progress on this question will necessitate within-subject analyses of the anatomical relationship between attention and retrieval effects in lateral parietal cortex, and, as implied above, will require additional specification of how shared component processes might be useful for remembering.

Beyond methodological concerns, a complete understanding of the role of lateral PPC during episodic retrieval will also come from critical evaluation of other hypothesized mechanisms, including the mnemonic accumulator and output buffer hypotheses. For example, the mnemonic accumulator hypothesis is compatible with evidence showing graded familiarity or memory strength effects in lateral PPC (e.g., Yonelinas et al. 2005), as well as with evidence suggesting that regions of IPS accumulate evidence in service of perceptual recognition decisions (Ploran et al. 2007). At present, it remains to be determined whether such a mechanism underlies the parietal old/new effect, or whether accumulator-like effects overlap with the dorsal attention network, rather than the lateral IPS regions that show old/new effects. With respect to the output buffer hypothesis, it has been recently argued that the recollection effects observed in AnG might reflect such a mechanism (Vilberg and Rugg [2008b]; for a similar proposal regarding SMG/TPJ, see Vincent et al. [2008]). This proposal is bolstered by fMRI data showing ventral parietal sensitivity to the amount of information recollected (Vilberg and Rugg 2007, 2008a,b; also see Hutchinson et al. 2008), as well as functional and anatomical connectivity data showing strong interconnection between the hippocampal formation and AnG (Vincent et al. 2006; Kahn et al. 2008; Vilberg and Rugg 2008b). Both the mnemonic accumulator and output buffer hypotheses suggest promising alternatives to strictly attention-related accounts of lateral PPC functioning in episodic retrieval and await further evaluation.

In summary, the aforementioned insights into parietal contributions to remembering advance our understanding of the relation between memory and attention, but also highlight that substantial mechanistic uncertainty remains. In an interesting parallel with the behavioral literature on attention and memory, the findings of this review and a separate review on encoding (Uncapher and Wagner 2009) suggest an asymmetry in the contributions of attention to episodic encoding and retrieval. Behavioral findings suggest that encoding relies more heavily on attention mechanisms than does retrieval (for review see Craik 2001). Likewise, Uncapher and Wagner (2009) suggest that an attention-based account of lateral parietal contributions to encoding is viable, whereas the present study suggests that this attention explanation might not fully extend to episodic retrieval. Given the diversity of higher cognitive functions putatively attributed to lateral PPC, along with the diversity of distinct parietal subregions, future research is bound to reveal the multi-process nature of parietal contributions to episodic retrieval. Because attempts to anatomically align or dissociate across-domain parietal responses are made difficult by across-study comparisons of normalized group data, we anticipate that a particularly fruitful path to further progress will be within-subject manipulations that directly test the degree of across-domain functional overlap. By focusing on individual functional anatomy, future functional imaging studies promise to unravel the current mystery surrounding the role of parietal cortex in remembering episodic experiences.

\section{Acknowledgments}

This work was supported by the National Institute of Mental Health (5R01MH080309 and 5R01MH076932) and the Alfred P. Sloan Foundation. We thank Itamar Kahn, Brice Kuhl, and Michael Silver for assistance with figure generation.

\section{References}

Allan KL, Wilding E, Rugg MD. 1998. Electrophysiological evidence for dissociable processes contributing to recollection. Acta Psychol (Amst) 98: $231-252$.

Andersen RA, Buneo CA. 2002. Intentional maps in posterior parietal cortex. Annu Rev Neurosci 25: 189-220.

Arrington CM, Carr TH, Mayer AR, Rao SM. 2000. Neural mechanisms of visual attention: Object-based selection of a region in space. J Cogn Neurosci (Suppl 2) 12: 106-117.

Astafiev SV, Shulman GL, Stanley CM, Snyder AA, Van Essen DC, Corbetta M. 2003. Functional organization of human intraparietal and frontal cortex for attending, looking, and pointing. J Neurosci 23: 4689-4699.

Baddeley A. 2000. The episodic buffer: A new component of working memory? Trends Cogn Sci 4: 417-423.

Bates E, Wilson SM, Saygin AP, Dick F, Sereno MI, Knight RT, Dronkers NF. 2003. Voxel-based lesion-symptom mapping. Nat Neurosci 6: 448-450.

Beauchamp MS, Petit L, Ellmore TM, Ingeholm J, Haxby JV. 2001. A parametric fMRI study of overt and covert shifts of visuospatial attention. Neuroimage 14: 310-321.

Behrmann M, Geng JJ, Shomstein S. 2004. Parietal cortex and attention. Curr Opin Neurobiol 14: 212-217.

Berryhill ME, Phuong L, Picasso L, Cabeza R, Olson IR. 2007. Parietal lobe and episodic memory: Bilateral damage causes impaired free recall of autobiographical memory. J Neurosci 27: 14415-14423.

Bledowski C, Prvulovic D, Goebel R, Zanella FE, Linden DEJ. 2004. Attentional systems in target and distractor processing: A combined ERP and fMRI study. Neuroimage 22: 530-540.

Braver TS, Barch DM, Gray JR, Molfese DL, Snyder A. 2001. Anterior cingulate cortex and response conflict: Effects of frequency, inhibition and errors. Cereb Cortex 11: 825-836.

Broadbent D. 1958. Perception and communication. Pergamon, New York.

Buckner RL. 2003. Functional-anatomic correlates of control processes in memory. J Neurosci 23: 3999-4004.

Buckner RL, Andrews-Hanna JR, Schacter DL. 2008. The brain's default network: Anatomy, function, and relevance to disease. Ann N Y Acad Sci 1124: $1-38$.

Bunge SA, Burrows B, Wagner AD. 2004. Prefrontal and hippocampal contributions to visual associative recognition: Interactions between cognitive control and episodic retrieval. Brain Cogn 56: 141-152.

Cabeza R. 2008. Role of parietal regions in episodic memory retrieval: The dual attentional processes hypothesis. Neuropsychologia 46: 1813-1827.

Cabeza R, Dolcos F, Prince SE, Rice HJ, Weissman DH, Nyberg L. 2003. Attention-related activity during episodic memory retrieval: A crossfunction fMRI study. Neuropsychologia 41: 390-399.

Cabeza R, Ciaramelli E, Olson IR, Moscovitch M. 2008. The parietal cortex and episodic memory: An attentional account. Nat Rev Neurosci 9: 613625.

Cansino S, Maquet P, Dolan RJ, Rugg MD. 2002. Brain activity underlying encoding and retrieval of source memory. Cereb Cortex 12: 1048-1056.

Cherry EC. 1953. Some experiments on the recognition of speech, with one and with two ears. J Acoust Soc Am 25: 975-979.

Christman SD, Garvey KJ, Propper RE, Phaneuf KA. 2003. Bilateral eye movements enhance the retrieval of episodic memories. Neuropsychology 17: 221-229.

Ciaramelli E, Grady CL, Moscovitch M. 2008. Top-down and bottom-up attention to memory: A hypothesis (AtoM) on the role of the posterior parietal cortex in memory retrieval. Neuropsychologia 46: 1828-1851.

Cipolloni PB, Pandya DN. 1999. Cortical connections of the frontoparietal opercular areas in the rhesus monkey. J Comp Neurol 403: 431-458.

Clark VP, Fannon S, Lai S, Benson R, Bauer L. 2000. Responses to rare visual target and distractor stimuli using event-related fMRI. J Neurophysiol 83: 3133-3139.

Colby CL, Goldberg ME. 1999. Space and attention in parietal cortex. Annu Rev Neurosci 22: 319-349.

Connolly JD, Goodale MA, Menon RS, Munoz DP. 2002. Human fMRI evidence for the neural correlates of preparatory set. Nat Neurosci 5: 1345-1352.

Constantinidis C, Steinmetz MA. 2001. Neuronal responses in area 7a to multiple-stimulus displays: I. Neurons encode the location of the salient stimulus. Cereb Cortex 11: 581-591.

Constantinidis C, Steinmetz MA. 2005. Posterior parietal cortex automatically encodes the location of salient stimuli. J Neurosci 25: 233-238.

Corbetta M, Shulman GL. 2002. Control of goal-directed and stimulusdriven attention in the brain. Nat Rev Neurosci 3: 201-215.

Corbetta M, Akbudak E, Conturo TE, Snyder AZ, Ollinger JM, Drury HA, Linenweber MR, Petersen SE, Raichle ME, Van Essen DC, et al. 1998. A common network of functional areas for attention and eye movements. Neuron 21: 761-773.

Corbetta M, Kincade JM, Ollinger JM, McAvoy MP, Shulman GL. 2000. Voluntary orienting is dissociated from target detection in human posterior parietal cortex. Nat Neurosci 3: 292-297. 
Corbetta M, Kincade JM, Shulman GL. 2002. Neural systems for visual orienting and their relationships to spatial working memory. J Cogn Neurosci 14: 508-523.

Corbetta M, Kincade M, Lewis C, Snyder AZ, Sapir A. 2005. Neural basis and recovery of spatial attention deficits in spatial neglect. Nat Neurosci 8: $1603-1610$.

Corbetta M, Patel G, Shulman GL. 2008. The reorienting system of the human brain: From environment to theory of mind. Neuron 58: 306324.

Coull JT, Frith CD. 1998. Differential activation of right superior parietal cortex and intraparietal sulcus by spatial and nonspatial attention. Neuroimage 8: $176-187$

Craik FIM. 2001. Effects of dividing attention on encoding and retrieval processes. In The nature of remembering: Essays in honor of Robert $G$. Crowder (ed. HL Roediger), pp. 55-68. American Psychological Association, New York.

Culham JC, Kanwisher N. 2001. Neuroimaging of cognitive functions in human parietal cortex. Curr Opin Neurobiol 11: 157-163.

Culham JC, Brandt SA, Cavanagh P, Kanwisher NG, Dale AM, Tootell RB. 1998. Cortical fMRI activation produced by attentive tracking of moving targets. J Neurophysiol 80: 2657-2670.

Curran T. 2000. Brain potentials of recollection and familiarity. Mem Cognit 28: 923-938.

Curran T, Cleary AM. 2003. Using ERPs to dissociate recollection from familiarity in picture recognition. Brain Res Cogn Brain Res 15: 191205.

Curtis CE. 2006. Prefrontal and parietal contributions to spatial working memory. Neuroscience 139: 173-180.

Curtis CE, Rao VY, D'Esposito M. 2004. Maintenance of spatial and motor codes during oculomotor delayed response tasks. J Neurosci 24: 3944 3952.

Davidson PS, Anaki D, Ciaramelli E, Cohn M, Kim AS, Murphy KJ, Troyer AK, Moscovitch M, Levine B. 2008. Does lateral parietal cortex support episodic memory? Evidence from focal lesion patients. Neuropsychologia 46: 1743-1755.

Dehaene S, Molko N, Cohen L, Wilson AJ. 2004. Arithmetic and the brain. Curr Opin Neurobiol 14: 218-224.

Desimone R, Duncan J. 1995. Neural mechanisms of selective visual attention. Annu Rev Neurosci 18: 193-222.

Dobbins IG, Wagner AD. 2005. Domain-general and domain-sensitive prefrontal mechanisms for recollecting events and detecting novelty. Cereb Cortex 15: 1768-1778.

Dobbins IG, Foley H, Schacter DL, Wagner AD. 2002. Executive control during episodic retrieval: Multiple prefrontal processes subserve source memory. Neuron 35: 989-996.

Dobbins IG, Rice HJ, Wagner AD, Schacter DL. 2003. Memory orientation and success: Separable neurocognitive components underlying episodic recognition. Neuropsychologia 41: 318-333.

Donaldson W. 1996. The role of decision processes in remembering and knowing. Mem Cognit 24: 523-533.

Donaldson DI, Petersen SE, Ollinger JM, Buckner RL. 2001. Dissociating state and item components of recognition memory using fMRI. Neuroimage 13: 129-142.

Downar J, Crawley AP, Mikulis DJ, Davis KD. 2000. A multimodal cortical network for the detection of changes in the sensory environment. Nat Neurosci 3: 277-283.

Dronkers NF, Wilkins DP, Van Valin RD, Redfern BB, Jaeger JJ. 2004. Lesion analysis of the brain areas involved in language comprehension. Cognition 92: 145-177.

Dudukovic NM, Wagner AD. 2007. Goal-dependent modulation of declarative memory: Neural correlates of temporal recency decisions and novelty detection. Neuropsychologia 45: 2608-2620.

Dunn JC. 2004. Remember-know: A matter of confidence. Psychol Rev 111: $524-542$.

Dunn JC. 2008. The dimensionality of the remember-know task: A statetrace analysis. Psychol Rev 115: 426-446.

Ehrlichman H, Micic D, Sousa A, Zhu J. 2007. Looking for answers: Eye movements in non-visual cognitive tasks. Brain Cogn 64: 7-20.

Eichenbaum H, Cohen N. 2001. From conditioning to conscious recollection: Memory systems of the brain. Oxford University Press, New York.

Eldridge LL, Knowlton BJ, Furmanski CS, Bookheimer SY, Engel SA. 2000. Remembering episodes: A selective role for the hippocampus during retrieval. Nat Neurosci 3: 1149-1152.

Fan J, Gay Snodgrass J, Bilder RM. 2003. Functional magnetic resonance imaging of source versus item memory. Neuroreport 14: 2275-2281.

Fletcher PC, Henson RN. 2001. Frontal lobes and human memory: Insights from functional neuroimaging. Brain 124: 849-881.

Fox MD, Corbetta M, Snyder AZ, Vincent JL, Raichle M. 2006. Spontaneous neuronal activity distinguishes human dorsal and ventral attention systems. Proc Natl Acad Sci 103: 10046-10051.

Gabrieli JD. 1998. Cognitive neuroscience of human memory. Annu Rev Psychol 49: 87-115.
Giesbrecht B, Woldorff MG, Song AW, Mangun GR. 2003. Neural mechanisms of top-down control during spatial and feature attention. Neuroimage 19: 496-512.

Goldberg ME, Bisley J, Powell KD, Gottlieb J, Kusunoki M. 2002. The role of the lateral intraparietal area of the monkey in the generation of saccades and visuospatial attention. Ann N Y Acad Sci 956: 205-215.

Hagler DJ, Sereno MI. 2006. Spatial maps in frontal and prefrontal cortex. Neuroimage 29: 567-577.

Hagler DJ, Riecke L, Sereno MI. 2007. Parietal and superior frontal visuospatial maps activated by pointing and saccades. Neuroimage 35: $1562-1577$.

Haramati S, Soroker N, Dudai Y, Levy DA. 2008. The posterior parietal cortex in recognition memory: A neuropsychological study. Neuropsychologia 46: $1756-1766$.

He BJ, Snyder AZ, Vincent JL, Epstein A, Shulman GL, Corbetta M. 2007. Breakdown of functional connectivity in frontoparietal networks underlies behavioral deficits in spatial neglect. Neuron 53: 905-918.

Heekeren HR, Marrett S, Bandettini PA, Ungerleider LG. 2004. A general mechanism for perceptual decision-making in the human brain. Nature 431: 859-862.

Henson RN, Rugg MD, Shallice T, Josephs O, Dolan RJ. 1999. Recollection and familiarity in recognition memory: An event-related functional magnetic resonance imaging study. J Neurosci 19: 3962-3972.

Henson RN, Hornberger M, Rugg MD. 2005. Further dissociating the processes involved in recognition memory: An fMRI study. J Cogn Neurosci 17: 1058-1073.

Herron JE, Henson RN, Rugg MD. 2004. Probability effects on the neural correlates of retrieval success: An fMRI study. Neuroimage 21: 302-310.

Hillis AE, Newhart M, Heidler J, Barker PB, Herskovits EH, Degaonkar M. 2005. Anatomy of spatial attention: Insights from perfusion imaging and hemispatial neglect in acute stroke. I Neurosci 25: 3161-3167.

Hopfinger JB, Buonocore MH, Mangun GR. 2000. The neural mechanisms of top-down attentional control. Nat Neurosci 3: 284-291.

Hubbard EM, Piazza M, Pinel P, Dehaene S. 2005. Interactions between number and space in parietal cortex. Nat Rev Neurosci 6: 435-448.

Huettel SA, Güzeldere G, McCarthy G. 2001. Dissociating the neural mechanisms of visual attention in change detection using functional MRI. J Cogn Neurosci 13: 1006-1018.

Husain M, Nachev P. 2007. Space and the parietal cortex. Trends Cogn Sci 11: 30-36.

Hutchinson J, Cristo Y, Preston A, Wagner AD. 2008. Frontal and parietal correlates of graded recollection during episodic recall. In Annual Meeting of the Cognitive Neuroscience Society. University of California, Davis, CA.

Iidaka T, Matsumoto A, Nogawa J, Yamamoto Y, Sadato N. 2006. Frontoparietal network involved in successful retrieval from episodic memory. Spatial and temporal analyses using fMRI and ERP. Cereb Cortex 16: $1349-1360$.

Indovina I, Macaluso E. 2007. Dissociation of stimulus relevance and saliency factors during shifts of visuospatial attention. Cereb Cortex 17: 1701

Jack AI, Patel GH, Astafiev SV, Snyder AZ, Akbudak E, Shulman GL, Corbetta M. 2007. Changing human visual field organization from early visual to extra-occipital cortex. PLoS One 2: e452. doi: 10.1371/journal.pone. 0000452 .

James W. 1890. The principles of psychology. Holt, New York.

Johnson MK, Hashtroudi S, Lindsay DS. 1993. Source monitoring. Psychol Bull 114: 3-28.

Jonides J, Schumacher EH, Smith EE, Koeppe RA, Awh E, Reuter-Lorenz PA, Marshuetz C, Willis CR. 1998. The role of parietal cortex in verbal working memory. J Neurosci 18: 5026-5034.

Kahn I, Davachi L, Wagner AD. 2004. Functional-neuroanatomic correlates of recollection: Implications for models of recognition memory. $J$ Neurosci 24: 4172-4180.

Kahn I, Andrews-Hanna JR, Vincent JL, Snyder AZ, Buckner RL. 2008. Distinct cortical anatomy linked to subregions of the medial temporal lobe revealed by intrinsic functional connectivity. J Neurophysiol 100: 129-139.

Kanwisher N, Wojciulik E. 2000. Visual attention: Insights from brain imaging. Nat Rev Neurosci 1: 91-100.

Kastner S, Ungerleider LG. 2000. Mechanisms of visual attention in the human cortex. Annu Rev Neurosci 23: 315-341.

Kastner S, Pinsk MA, De Weerd P, Desimone R, Ungerleider LG. 1999. Increased activity in human visual cortex during directed attention in the absence of visual stimulation. Neuron 22: 751-761.

Kensinger EA, Schacter DL. 2006. Neural processes underlying memory attribution on a reality-monitoring task. Cereb Cortex 16: 1126-1133.

Kiehl KA, Laurens KR, Duty TL, Forster BB, Liddle PF. 2001. Neural sources involved in auditory target detection and novelty processing: An eventrelated fMRI study. Psychophysiology 38: 133-142.

Kincade JM, Abrams RA, Astafiev SV, Shulman GL, Corbetta M. 2005. An event-related functional magnetic resonance imaging study of 
voluntary and stimulus-driven orienting of attention. J Neurosci 25: 4593-4604.

Knudsen EI. 2007. Fundamental components of attention. Annu Rev Neurosci 30: 57-78.

Konen CS, Kastner S. 2008a. Representation of eye movements and stimulus motion in topographically organized areas of human posterior parietal cortex. J Neurosci 28: 8361-8375.

Konen CS, Kastner S. 2008b. Two hierarchically organized neural systems for object information in human visual cortex. Nat Neurosci 11: 224231.

Konishi S, Wheeler ME, Donaldson DI, Buckner RL. 2000. Neural correlates of episodic retrieval success. Neuroimage 12: 276-286.

Kuhl BA, Dudukovic NM, Kahn I, Wagner AD. 2007. Decreased demands on cognitive control reveal the neural processing benefits of forgetting. Nat Neurosci 10: 908-914.

Kuhl BA, Kahn I, Dudukovic NM, Wagner AD. 2008. Overcoming suppression in order to remember: Contributions from anterior cingulate and ventrolateral prefrontal cortex. Cogn Affect Behav Neurosci 8: 211-221.

Kurby CA, Zacks JM. 2008. Segmentation in the perception and memory of events. Trends Cogn Sci 12: 72-79.

Le TH, Pardo JV, Hu X. 1998. 4T-fMRI study of nonspatial shifting of selective attention: Cerebellar and parietal contributions. J Neurophysiol 79: $1535-1548$.

Leube DT, Erb M, Grodd W, Bartels M, Kircher TT. 2003. Successful episodic memory retrieval of newly learned faces activates a left fronto-parietal network. Brain Res Cogn Brain Res 18: 97-101.

Leveroni CL, Seidenberg M, Mayer AR, Mead LA, Binder JR, Rao SM. 2000. Neural systems underlying the recognition of familiar and newly learned faces. J Neurosci 20: 878-886.

Levy BJ, Anderson MC. 2009. The control of mnemonic awareness. In The encyclopedia of consciousness (ed. W Banks). Academic Press, San Diego, CA (in press).

Levy I, Schluppeck D, Heeger DJ, Glimcher PW. 2007. Specificity of human cortical areas for reaches and saccades. J Neurosci 27: 4687-4696.

Lewis JW, Van Essen DC. 2003. Corticocortical connections of visual, sensorimotor, and multimodal processing areas in the parietal lobe of the macaque monkey. J Comp Neurol 428: 112-137.

Linden DE, Prvulovic D, Formisano E, Völlinger M, Zanella FE, Goebel R, Dierks T. 1999. The functional neuroanatomy of target detection: An fMRI study of visual and auditory oddball tasks. Cereb Cortex 9: 815823.

Liu T, Slotnick SD, Serences JT, Yantis S. 2003. Cortical mechanisms of feature-based attentional control. Cereb Cortex 13: 1334-1343.

Lundstrom BN, Petersson KM, Andersson J, Johansson M, Fransson P, Ingvar M. 2003. Isolating the retrieval of imagined pictures during episodic memory: Activation of the left precuneus and left prefrontal cortex. Neuroimage 20: 1934-1943.

Macaluso E, Patria F. 2007. Spatial re-orienting of visual attention along the horizontal or the vertical axis. Exp Brain Res 180: 23-34.

Macaluso E, Frith CD, Driver J. 2002. Supramodal effects of covert spatial orienting triggered by visual or tactile events. J Cogn Neurosci 14: 389401.

Marois R, Chun MM, Gore JC. 2000a. Neural correlates of the attentional blink. Neuron 28: 299-308.

Marois R, Leung HC, Gore JC. 2000b. A stimulus-driven approach to object identity and location processing in the human brain. Neuron 25: 717728.

Mayer AR, Harrington D, Adair JC, Lee R. 2006. The neural networks underlying endogenous auditory covert orienting and reorienting. Neuroimage 30: 938-949.

McCarthy G, Luby M, Gore JC, Goldman-Rakic P. 1997. Infrequent events transiently activate human prefrontal and parietal cortex as measured by functional MRI. J Neurophysiol 77: 1630-1634.

McDermott KB, Jones TC, Petersen SE, Lageman SK, Roediger HL. 2000. Retrieval success is accompanied by enhanced activation in anterior prefrontal cortex during recognition memory: An event-related fMRI study. J Cogn Neurosci 12: 965-976.

Menon V, Ford JM, Lim KO, Glover GH, Pfefferbaum A. 1997. Combined event-related fMRI and EEG evidence for temporal-parietal cortex activation during target detection. Neuroreport 8: 3029-3037.

Mesulam MM. 1999. Spatial attention and neglect: Parietal, frontal and cingulate contributions to the mental representation and attentional targeting of salient extrapersonal events. Philos Trans $R$ Soc Lond B Biol Sci 354: 1325-1346.

Molenberghs P, Mesulam MM, Peeters R, Vandenberghe RR. 2007. Remapping attentional priorities: Differential contribution of superior parietal lobule and intraparietal sulcus. Cereb Cortex 17: 2703-2712.

Montaldi D, Spencer T, Roberts N, Mayes A. 2006. The neural system that mediates familiarity memory. Hippocampus 16: 504-520.

Mort DJ, Malhotra P, Mannan SK, Rorden C, Pambakian A, Kennard C, Husain M. 2003. The anatomy of visual neglect. Brain 126: 1986-1997.
Olson IR, Berryhill M. 2009. Some surprising findings on the involvement of the parietal lobe in human memory. Neurobiol Learn Mem 91: 155165.

Pandya DN, Seltzer B. 1982. Intrinsic connections and architectonics of posterior parietal cortex in the rhesus monkey. J Comp Neurol 204: 196210.

Parton A, Malhotra P, Husain M. 2004. Hemispatial neglect. J Neurol Neurosurg Psychiatr 75: 13-21.

Pessoa L, Gutierrez E, Bandettini P, Ungerleider L. 2002. Neural correlates of visual working memory: fMRI amplitude predicts task performance. Neuron 35: 975-987.

Pessoa L, Kastner S, Ungerleider LG. 2003. Neuroimaging studies of attention: From modulation of sensory processing to top-down control. J Neurosci 23: 3990-3998.

Ploran EJ, Nelson SM, Velanova K, Donaldson DI, Petersen SE, Wheeler ME. 2007. Evidence accumulation and the moment of recognition: Dissociating perceptual recognition processes using fMRI. J Neurosci 27: 11912-11924.

Posner MI. 1980. Orienting of attention. The VII Sir Frederick Bartlett lecture. Quart J Exp Psychol 32: 3-25.

Posner MI, Driver J. 1992. The neurobiology of selective attention. Curr Opin Neurobiol 2: 165-169.

Posner MI, Petersen SE. 1990. The attention system of the human brain. Annu Rev Neurosci 13: 25-42.

Posner MI, Walker JA, Friedrich FJ, Rafal RD. 1984. Effects of parietal injury on covert orienting of attention. J Neurosci 4: 1863-1874.

Ragland JD, Gur RC, Valdez J, Turetsky BI, Elliott M, Kohler C, Siegel S, Kanes S, Gur RE. 2004. Event-related fMRI of frontotemporal activity during word encoding and recognition in schizophrenia. Am J Psychiatry 161: 1004-1015.

Ragland JD, Valdez JN, Loughead J, Gur RC, Gur RE. 2006. Functional magnetic resonance imaging of internal source monitoring in schizophrenia: Recognition with and without recollection. Schizophr Res 87: 160-171.

Ranganath C, Knight RT. 2002. Prefrontal cortex and episodic memory: Integrating findings from neuropsychology and functional brain imaging. In The cognitive neuroscience of memory: Encoding and retrieval (eds. A Parker et al.), pp. 83-99. Psychology Press, New York.

Raye CL, Johnson MK, Mitchell KJ, Greene EJ, Johnson MR. 2007. Refreshing: A minimal executive function. Cortex 43: 135-145.

Rossi S, Pasqualetti P, Zito G, Vecchio F, Cappa SF, Miniussi C, Babiloni C, Rossini PM. 2006. Prefrontal and parietal cortex in human episodic memory: An interference study by repetitive transcranial magnetic stimulation. Eur J Neurosci 23: 793-800.

Rowe JB, Toni I, Josephs O, Frackowiak RS, Passingham RE. 2000. The prefrontal cortex: Response selection or maintenance within working memory? Science 288: 1656-1660.

Rugg MD, Curran T. 2007. Event-related potentials and recognition memory. Trends Cogn Sci 11: 251-257.

Rugg MD, Yonelinas AP. 2003. Human recognition memory: A cognitive neuroscience perspective. Trends Cogn Sci 7: 313-319.

Rushworth MF, Johansen-Berg H, Göbel SM, Devlin JT. 2003. The left parietal and premotor cortices: Motor attention and selection. Neuroimage 20: S89-S100.

Rushworth MF, Behrens TE, Johansen-Berg H. 2006. Connection patterns distinguish three regions of human parietal cortex. Cereb Cortex 16: 1418-1430.

Sapir A, d'Avossa G, McAvoy M, Shulman GL, Corbetta M. 2005. Brain signals for spatial attention predict performance in a motion discrimination task. Proc Natl Acad Sci 102: 17810-17815.

Saygin AP, Sereno MI. 2008. Retinotopy and attention in human occipital, temporal, parietal, and frontal cortex. Cereb Cortex 18: 2158-2168.

Scheperjans F, Eickhoff SB, Hömke L, Mohlberg H, Hermann K, Amunts K, Zilles K. 2008. Probabilistic maps, morphometry, and variability of cytoarchitectonic areas in the human superior parietal cortex. Cereb Cortex 18: 2141-2157.

Schluppeck D, Glimcher P, Heeger DJ. 2005. Topographic organization for delayed saccades in human posterior parietal cortex. J Neurophysiol 94: $1372-1384$.

Schluppeck D, Curtis CE, Glimcher PW, Heeger DJ. 2006. Sustained activity in topographic areas of human posterior parietal cortex during memory-guided saccades. J Neurosci 26: 5098-5108.

Schmahmann JD, Pandya DN, Wang R, Dai G, D'Arceuil HE, de Crespigny AJ, Wedeen VJ. 2007. Association fibre pathways of the brain: Parallel observations from diffusion spectrum imaging and autoradiography. Brain 130: 630-653.

Seltzer B, Pandya DN. 1986. Posterior parietal projections to the intraparietal sulcus of the rhesus monkey. Exp Brain Res 62: 459-469.

Serences JT, Boynton GM. 2007. Feature-based attentional modulations in the absence of direct visual stimulation. Neuron 55: 301-312.

Serences JT, Schwarzbach J, Courtney SM, Golay X, Yantis S. 2004. Control of object-based attention in human cortex. Cereb Cortex 14: 1346-1357. 
Serences JT, Shomstein S, Leber AB, Golay X, Egeth HE, Yantis S. 2005 Coordination of voluntary and stimulus-driven attentional control in human cortex. Psychol Sci 16: 114-122.

Sereno MI, Pitzalis S, Martinez A. 2001. Mapping of contralateral space in retinotopic coordinates by a parietal cortical area in humans. Science 294: $1350-1354$.

Shadlen MN, Newsome WT. 2001. Neural basis of a perceptual decision in the parietal cortex (area LIP) of the rhesus monkey. J Neurophysiol 86: 1916-1936.

Shannon BJ, Buckner RL. 2004. Functional-anatomic correlates of memory retrieval that suggest nontraditional processing roles for multiple distinct regions within posterior parietal cortex. J Neurosci 24: 10084 10092.

Sharot T, Delgado MR, Phelps EA. 2004. How emotion enhances the feeling of remembering. Nat Neurosci 7: 1376-1380.

Shimamura AP. 1995. Memory and the prefrontal cortex. Ann N Y Acad Sci 769: $151-159$.

Shulman GL, Ollinger JM, Akbudak E, Conturo TE, Snyder AZ, Petersen SE, Corbetta M. 1999. Areas involved in encoding and applying directional expectations to moving objects. J Neurosci 19: 9480-9496.

Shulman GL, d'Avossa G, Tansy AP, Corbetta M. 2002. Two attentional processes in the parietal lobe. Cereb Cortex 12: 1124-1131.

Shulman GL, McAvoy MP, Cowan MC, Astafiev SV, Tansy AP, d'Avossa G, Corbetta M. 2003. Quantitative analysis of attention and detection signals during visual search. J Neurophysiol 90: 3384-3397.

Silver MA, Ress D, Heeger DJ. 2005. Topographic maps of visual spatial attention in human parietal cortex. J Neurophysiol 94: 1358-1371.

Simons JS, Peers PV, Hwang DY, Ally BA, Fletcher PC, Budson AE. 2008. Is the parietal lobe necessary for recollection in humans? Neuropsychologia 46: 1185-1191.

Smith ME. 1993. Neurophysiological manifestations of recollective experience during recognition memory judgments. J Cogn Neurosci 5: 113.

Squire LR. 1992. Memory and the hippocampus: A synthesis from findings with rats, monkeys, and humans. Psychol Rev 99: 195-231.

Squire LR, Stark CE, Clark RE. 2004. The medial temporal lobe. Annu Rev Neurosci 27: 279-306.

Stevens MC, Calhoun VD, Kiehl KA. 2005. Hemispheric differences in hemodynamics elicited by auditory oddball stimuli. Neuroimage 26: 782-792.

Strange BA, Dolan RJ. 2007. $\beta$-Adrenergic modulation of oddball responses in humans. Behav Brain Funct 3: 29-33.

Sugrue LP, Corrado GS, Newsome WT. 2005. Choosing the greater of two goods: Neural currencies for valuation and decision-making. Nat Rev Neurosci 6: 363-375.

Swisher JD, Halko MA, Merabet LB, McMains SA, Somers DC. 2007. Visual topography of human intraparietal sulcus. J Neurosci 27: 5326-5337.

Sylvester CM, Shulman GL, Jack AI, Corbetta M. 2007. Asymmetry of anticipatory activity in visual cortex predicts the locus of attention and perception. J Neurosci 27: 14424-14433.

Treisman AM, Gelade G. 1980. A feature-integration theory of attention. Cognit Psychol 12: 97-136.

Tsukiura T, Mochizuki-Kawai H, Fujii T. 2005. The effect of encoding strategies on medial temporal lobe activations during the recognition of words: An event-related fMRI study. Neuroimage 25: 452-461.

Tulving E. 1985. Memory and consciousness. Can Psychol 26: 1-12.

Uncapher MR, Wagner AD. 2009. Posterior parietal cortex and episodic encoding: Insights from fMRI subsequent memory effects and dualattention theory. Neurobiol Learn Mem 91: 139-154.

Van Essen DC. 2005. A population-average, landmark- and surface-based (PALS) atlas of human cerebral cortex. Neuroimage 28: 635-662.

Van Essen DC, Drury HA, Dickson J, Harwell J, Hanlon D, Anderson CH. 2001. An integrated software suite for surface-based analyses of cerebral cortex. J Am Med Inform Assoc 8: 443-459.
Vilberg KL, Rugg MD. 2007. Dissociation of the neural correlates of recognition memory according to familiarity, recollection, and amount of recollected information. Neuropsychologia 45: 2216-2225.

Vilberg KL, Rugg MD. 2008a. Functional significance of retrieval-related activity in lateral parietal cortex: Evidence from fMRI and ERPs. Hum. Brain Mapp. 30: 1490-1501.

Vilberg KL, Rugg MD. 2008b. Memory retrieval and the parietal cortex: A review of evidence from a dual-process perspective. Neuropsychologia 46: 1787-1799.

Vincent JL, Snyder AZ, Fox MD, Shannon BJ, Andrews JR, Raichle ME, Buckner RL. 2006. Coherent spontaneous activity identifies a hippocampal-parietal memory network. J Neurophysiol 96: 35173531 .

Vincent JL, Kahn I, Snyder AZ, Raichle ME, Buckner RL. 2008. Evidence for a frontoparietal control system revealed by intrinsic functional connectivity. J Neurophysiol 100: 3328-3342.

von Zerssen GC, Mecklinger A, Opitz B, von Cramon DY. 2001. Conscious recollection and illusory recognition: An event-related fMRI study. Eur I Neurosci 13: 2148-2156.

Vossel S, Thiel CM, Fink GR. 2006. Cue validity modulates the neural correlates of covert endogenous orienting of attention in parietal and frontal cortex. Neuroimage 32: 1257-1264.

Wagner AD. 1999. Working memory contributions to human learning and remembering. Neuron 22: 19-22.

Wagner AD, Shannon BJ, Kahn I, Buckner RL. 2005. Parietal lobe contributions to episodic memory retrieval. Trends Cogn Sci 9: 445-453.

Wais PE, Mickes L, Wixted J. 2008. Remember/know judgments probe degrees of recollection. J Cogn Neurosci 20: 400-405.

Weis S, Klaver P, Reul J, Elger CE, Fernández G. 2004. Temporal and cerebellar brain regions that support both declarative memory formation and retrieval. Cereb Cortex 14: 256-267.

Wheeler ME, Buckner RL. 2003. Functional dissociation among components of remembering: Control, perceived oldness, and content. J Neurosci 23: 3869-3880.

Wheeler ME, Buckner RL. 2004. Functional-anatomic correlates of remembering and knowing. Neuroimage 21: 1337-1349.

Wheeler MA, Stuss DT, Tulving E. 1995. Frontal lobe damage produces episodic memory impairment. J Int Neuropsychol Soc 1: 525-536.

Wilding EL, Doyle MC, Rugg MD. 1995. Recognition memory with and without retrieval of context: An event-related potential study. Neuropsychologia 33: 743-767.

Wise SP, Boussaoud D, Johnson PB, Caminiti R. 1997. Premotor and parietal cortex: Corticocortical connectivity and combinatorial computations. Annu Rev Neurosci 20: 25-42.

Wixted J. 2007. Dual-process theory and signal-detection theory of recognition memory. Psychol Rev 114: 152-176.

Wojciulik E, Kanwisher N. 1999. The generality of parietal involvement in visual attention. Neuron 23: 747-764.

Woodruff CC, Johnson JD, Uncapher MR, Rugg MD. 2005. Contentspecificity of the neural correlates of recollection. Neuropsychologia 43: 1022-1032.

Woodruff CC, Hayama HR, Rugg MD. 2006. Electrophysiological dissociation of the neural correlates of recollection and familiarity. Brain Res 1100: 125-135.

Yantis S, Serences JT. 2003. Cortical mechanisms of space-based and objectbased attentional control. Curr Opin Neurobiol 13: 187-193.

Yonelinas AP. 2002. The nature of recollection and familiarity: A review of 30 years of research. J Mem Lang 46: 441-517.

Yonelinas AP, Otten LJ, Shaw KN, Rugg MD. 2005. Separating the brain regions involved in recollection and familiarity in recognition memory. J Neurosci 25: 3002-3008.

Received October 23, 2008; accepted in revised form March 25, 2009. 


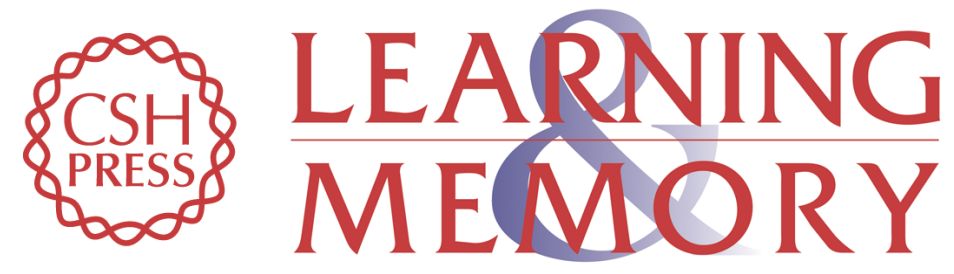

\section{Posterior parietal cortex and episodic retrieval: Convergent and divergent effects of attention and memory}

J. Benjamin Hutchinson, Melina R. Uncapher and Anthony D. Wagner

Learn. Mem. 2009, 16:

Access the most recent version at doi:10.1101//m.919109

References This article cites 190 articles, 28 of which can be accessed free at:

http://learnmem.cshlp.org/content/16/6/343.full.html\#ref-list-1

License

Email Alerting Receive free email alerts when new articles cite this article - sign up in the box at the Service top right corner of the article or click here. 